
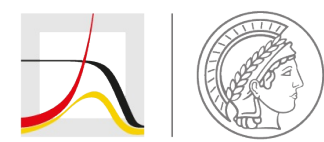

MAX PLANCK INSTITUTE

FOR DEMOGRAPHIC RESEARCH

Konrad-Zuse-Strasse 1 · D-18057 Rostock · Germany · Tel +49 (0) 3812081 - $0 \cdot$ Fax +49 (0) 3812081 - $202 \cdot$ www.demogr.mpg.de

MPIDR Working Paper WP 2020-017 I April 2020

https://doi.org/10.4054/MPIDR-WP-2020-017

\title{
Birth order pairings and romantic success
}

Seymour Spilerman I ss50@columbia.edu

Kieron Barclay I barclay@demogr.mpg.de

(c) Copyright is held by the authors.

Working papers of the Max Planck Institute for Demographic Research receive only limited review. Views or opinions expressed in working papers are attributable to the authors and do not necessarily reflect those of the Institute. 


\title{
BIRTH ORDER PAIRINGS AND ROMANTIC SUCCESS
}

Seymour Spilerman ${ }^{1, \star}$ and Kieron Barclay ${ }^{2,3, \dagger}$

${ }^{1}$ Department of Sociology, Columbia University

${ }^{2}$ Max Planck Institute for Demographic Research

${ }^{3}$ Department of Sociology, Stockholm University

†ss50@columbia.edu

†barclay@mpidr.de

\begin{abstract}
The possibility that birth order influences romantic compatibility has long intrigued the lay public. In the absence of empirical research a marital advise literature has emerged, based on the observations of counselors and clinical psychologists, which purports to explain marital success in terms of birth order pairings. The present paper has two parts. In the first, using population register data from Sweden, we investigate the propositions about birth order and romantic relationships that are prevalent in the popular literature and show they have little validity. In the second, we undertake our own analysis which reveals two major birth order impacts: (a) a pronounced only-child effect, in that couples in which either spouse is an only have a divorce rate notably higher than couples in which neither is an only-child; and (b) for males, a protective effect from divorce from marriage with a firstborn female, an outcome that does not hold for females in their own pairing choices.
\end{abstract}




\section{INTRODUCTION}

The possibility that birth order influences romantic compatibility has long intrigued the lay public. First proposed by Walter Toman a half century ago, based on earlier insights by Alfred Adler $(1928 ; 1937)$ about the purported linkage between birth order and coping style, Toman $(1959 ; 1961)$ extended Adler's observations to encompass pairings of birth orders, essentially proposing a theory about which couplings will be harmonious and which will be conflictual and stressful.

Toman's contentions, amplified by the writings of later clinical psychologists and marital counselors, have generated a robust popular literature about birth order effects in romantic settings. Indeed, a Google search of the joint terms "birth order" and "romance" yields some 1.3 million entries, with citations to a variety of newspapers, magazines, and web sites, and with titles such as "What Your Birth Order Can Tell You About Your Love Life" (Huffington Post 2017); "How Birth Order Affects Your Marriage" (Focus on the Family 2015); "Does Birth Order Make or Break a Relationship" (CBSnews 2011). Even the financial outlet Business Insider (2017) carried an article on this theme: "Who You Should Marry Based on Your Birth Order."

Despite the wide interest in this topic little empirical research has been carried out to assess the validity of the contentions. One result of this lacuna in our knowledge has been the occasion for an advise literature to emerge that purports to explain the mysteries of romantic compatibility in terms of the suitability of different birth order combinations. And in the absence of empirical evidence, the embracement of these contentions by the lay public has largely rested on the aura of expertise of clinical practitioners--their academic credentials and experience as psychologists and marriage counselors. In the present paper, our intent is to examine their claims using a large data set and, further, to supplement this assessment with our own analysis of the role of birth order in contributing to romantic success. 
If there has been little empirical study of birth order in romantic settings, this is not the case for birth order effects more generally. Since Francis Galton's (1874) observation that first borns and only children are overrepresented among eminent scholars, social scientists have sought to gauge the consequences of birth order, especially for cognitive outcomes. While early reviews produced conflicting assessments of whether a birth order effect even exists--see Adams (1972) and Schooler (1972)--many of those investigations were deficient in methodological formulation, either by a failure to adequately take account of sibship size (e.g., Record, et. al. 1969; Travis and Kohli 1995) or in the omission of factors that are correlated with birth order and predict the outcome variable (e.g., Breland 1974; Belmont and Marolla 1973). Recent research has avoided these pitfalls, even utilized fixed effects designs that control for unobserved family characteristics. These studies consistently reveal an impact of birth order on facets of achievement (e.g., Conley 2004; Kantarevic and Mechoulan 2006; Mechoulan and Wolff 2015; Black et. al., 2005; Barclay 2015), and are responsible for shifting the agenda from an inquiry into the existence of birth order effects to an assessment of how consequential they are, and for which sorts of outcome variables--see Steelman et. al. (2002) for a nuanced examination of the issues.

While the bulk of research has focused on aspects of cognitive attainment, there has been some exploration of the non-cognitive impacts of birth order, especially on psychological dispositions. Adler $(1928 ; 1937)$ first raised the possibility that particular personality traits are associated with birth order position. The operative mechanisms, according to Adler, are the experiences of "dethronement" by the first born from the privileged position of having a monopoly of parental time; the competition of the middle born for parental attention while squeezed between older and younger siblings; and the return of the last born to a privileged status as the older siblings depart from the household. Each of these early life experiences presumably imparts a particular coping style that is drawn upon later, in adult life. 
Empirical assessments of the non-cognitive effects of birth order have been decidedly mixed. What appears to be the case is that when the focus is on the "big five" dimensions of personality--a traditional formulation in psychology--there is little evidence of a birth order effect (e.g. Rohrer et. al. 2015; Bleske-Rechek and Kelly 2014; Jefferson et. al 1998; Gordon 2012, though see Black et. al. 2017 for a counter claim). But when the formulation of non-cognitive outcomes is extended to include social traits and interaction styles, support is forthcoming (e.g., Salmon et. al. 2016; Sills 2010; Paulhus et. al. 1999; Pollet et. al. 2010; Black et. al. 2017), though see Freese, et. al. (1999) for a contrary assessment. Moreover, several of the latter studies used within-family designs and the recent comprehensive investigation by Black (2017) was based on a very large, nationally representative data set.

There is a subsidiary literature in the non-cognitive domain that has theorized about the impact of birth order in romantic settings. Most influential is Toman's $(1959,1961)$ "duplication and complementarity principle," which posits that in romantic relationships individuals utilize the coping styles developed in childhood, in interactions with siblings. According to Toman, what is most efficacious for romantic success is that the pairing of the birth order constellations of the partners are complementary. A propitious pairing might, for example, join a first born male raised with a younger sister to a last born female raised with an older brother. While the implied dominance relation in this pairing might reflect the gender stereotypes of the 1950s, the time Toman was writing, his notion of duplication of the sibship dynamic and complementarity of the interpersonal coping styles is evident.

Attempts to empirically verify Toman's contentions have failed to find much support (e.g., Birtchnell and Mayhew 1977; Forer 1969; Bloser 1993; Gold and Dobson 1988), though see Weller et. al. (1974) and Mendelsohn, et. al. (1974) for contrary assessments. As noted earlier, this has not hindered the emergence of a robust popular literature on the import of birth order matching for romantic success. 
For scientific credibility this literature has referenced the writings of psychologists and marital counselors, some of whom have constructed their own typologies of auspicious and portentous pairings. The various typologies purport to derive from the clinical experiences of the practitioners, supplemented by a few empirical studies, usually with small convenience samples. This evidentially thin set of research underpinnings has been invoked in support of the extensive popular literature. A superficial appraisal of this body of work suggests that its contentions are eminently plausible, if not beguiling; after all, if there are personality differences among children that are linked to birth order, why should they not persist into adulthood and influence the success of romantic unions? This presumption is the underlying premise of the literature. Indeed, some of the claims about specific pairings might well hold true, but unlike the study of birth order effects on cognitive outcomes there has been little empirical examination of the contentions with respect to romantic unions.

A possible reason for the neglect of this topic is that the investigation of birth order effects in a romantic setting is a challenging undertaking. It is not individual outcomes that need to be examined but the results of couplings of the birth orders of two individuals. This generates a variety of pairing possibilities and requires a very large data set for the many combinations to be effectively analyzed. An investigation of this sort was recently undertaken by Barclay and Spilerman (2020) using Sweden's administrative register data. The units of observation were married couples, and the measure of (lack of) compatibility was the likelihood of divorce. However, the Barclay and Spilerman analysis focused on the additive effects of spouses' birth orders on divorce outcomes and did not address pairing effects--interactions of the birth orders in a marital union. It is these latter effects, however, that are at the heart of the contentions about romantic success, and it is the examination of these pairing effects that is the focus of the present paper. 
In the next section we discuss some conceptual issues, describe the data used in the study and outline our analytic strategy. We then assess the contentions about birth order and romantic success that appear in the popular literature. The formulations we examine essentially span this body of work; consequently we view our undertaking as addressing the validity of the corpus of literature on the topic, not just the claims of the specific psychologists and marital counselors that we review. In the final sections we report results from our own empirical analysis of birth order pairings and romantic success, as indexed by the divorce rate.

\section{CONCEPTUALIZATION, DATA, AND ANALYTIC STRATEGY}

To assess the popular literature on birth order and romantic compatibility we turned to 'Google' and 'Amazon Books' to identify the most influential formulations. Item rankings on both Google and Amazon are governed by proprietary algorithms in which popularity is enumerated as one of the principal factors determining the ranking of a web page or a listed book. An examination of the results reveals that the myriad claims about birth order effects in romantic relationships derive from a rather small number of competing formulations about compatible unions.

A Google search with the terms "birth order" and "romance" yielded 1.3 million entries; a query of "birth order" and "marriage" returned 1.4 million items. The content of the first 100 entries in each of these searches was examined to see whether the web page contained an account of romantic success in terms of a comprehensive list of birth order pairings. Because of extensive item duplication in the two searches, a total of 119 unique web pages were generated. Of these, 27 cited Kevin Leeman as the source of the account of birth order pairing and romantic success, 16 cited William Cane, and 9 referenced Linda Blair. The remaining citations were to authors with only an incidental focus on romantic success within a general discussion of birth order effects (e.g., Isaacson 
and Schneider 2004), or to authors who proposed pairing outcomes that largely duplicate those of the more cited individuals (e.g., Richardson and Richardson 1990).

An analogous interrogation of Amazon Books yielded only one item, a publication by Kevin Leeman. Broadening the search to "birth order" was more fruitful--Amazon's categories are less detailed than Google's. The first two entries were to books by Leeman--a prolific author on birth order effects, next was a book by Linda Blair, and Cane's publication appeared as item 18. The intervening items, 4-17, were either to general books on birth order in which romantic compatibility was mentioned only in passing, or to extended examinations of single birth order positions such as the first born child (Schuitemaker and Enthoven 2016). The items following number 18 were of a similar sort. Thus, the results from both the Google and Amazon searches point to the formulations of Kevin Leeman (2009), Linda Blair (2011), and William Cane (2008) as dominating the discourse on birth order pairings in romantic relationships. It is the contentions of these authors, along with the influential earlier formulation of Walter Toman (1961), that are examined in the first half of this paper.

Data and analytic approach. The data used in this study are Swedish administrative files. Since every resident in the country has a unique identification number we were able to link the administrative registers covering income, welfare receipts, education, civil status, and health. For our investigation a key data file is the Swedish multigenerational register, which makes it possible to link individuals to their parents as well as to other kin. Using these data we were able to identify all brothers and sisters, and calculate birth order and the size of the sibling group. We define a sibling group as a collection of individuals who share a biological mother and a biological father.

To reduce the complexity in our analysis of birth order effects on divorce we limited the study to first marriages by husband and by wife, thereby avoiding complications from the detritus associated with a failed earlier union. We examined the marital histories associated with first 
marriages during the period 1990 to 2012 for the cohort born between 1950 and 1990. Although register data are available from before 1990, the information for the control variables is much improved after that year. We do not include cohabitating couples who never married since Sweden did not develop a continuous dwelling register until 2011.

We further restricted the analysis to individuals born in Sweden who have Swedish born parents. Since immigrants bring their own customs regarding marriage preference and divorce behavior, we chose to restrict the study to the more homogenous population of native-born Swedes. We also excluded couples where either husband or wife was raised in a household where a parent had a child from an earlier union, since half-siblings and step-siblings muddy the assignment of birth order and alter the association of ordinal position with a particular array of experiences within the family. For the same reason we dropped couples where either partner came from a sibship in which there was a twin birth.

After imposing these restrictions, our analytical sample consisted of 235,208 couples in first marriages over the period 1990-2012, of whom 31,272 experienced divorce during this interval.

Piecewise constant exponential model. To study the relationship between birth order pairings and the risk of divorce, we employ survival analysis in the form of a piecewise constant regression model. The hazard function--the probability that individual i experiences an event (divorce) during the interval $[t, t+\Delta t]$, given that no event occurred before $t-$-is defined as:

$$
h_{i}\left(t \mid X_{i}\right)=\lim _{\Delta t \rightarrow 0} \frac{\operatorname{Pr}\left(t \leq T<t+\Delta t \mid T \geq t ; \mathbf{X}_{i}\right)}{\Delta t}
$$

where $\mathbf{X}$ is a vector of covariates. The piecewise constant exponential model, itself, can be written as

$$
\mathrm{h}_{\mathrm{ij}}\left(\mathrm{t} \mid \mathbf{X}_{\mathrm{i}}\right)=\lambda_{\mathrm{j}} \exp \left(\mathbf{X}_{\mathrm{i}}^{\prime} \boldsymbol{\beta}\right)
$$


where $\boldsymbol{\beta}$ is a vector of regression parameters (log hazard ratios) and the hazard rate for the i-th subject depends on the constant $\lambda_{\mathrm{j}}$, which varies over the observation period of the study.

The coefficient array $\mathbf{X}$ contains the components, $\mathbf{X}=\left(\mathbf{B} \mathbf{O}_{\mathbf{h}}, \mathbf{B} \mathbf{O}_{\mathrm{w}}, \mathbf{B O}_{\mathbf{h w}} ; \mathbf{Z}_{\mathbf{h}}, \mathbf{Z}_{\mathrm{w}}, \mathbf{Z}_{\mathbf{h w}}\right)$, where $\mathbf{B O}_{\mathbf{h}}$ is vector of birth order terms for husband, $\mathbf{B \mathbf { O } _ { w }}$ is an analogous vector for wife, $\mathbf{B} \mathbf{O}_{\mathbf{h w}}$ is a vector of interaction terms (pairings of husband's and wife's birth orders), and the $\mathbf{Z}$ variates are vectors of husband's and wife's characteristics and the characteristics of their parents. The vector $\mathbf{Z}_{\mathrm{hw}}$ contains terms common to both husband and wife (e.g., year of marriage) as well as terms computed from their individual characteristics (e.g., age difference between husband and wife). In this formulation, divorce is the event of interest while death of a partner or remaining married at the end of the study are censored events.

Covariates. We control for a number of variables that previous literature reviews (Härkönen 2014; Lyngstad and Jalovaara 2010) have cited as critical factors in regard to divorce risk. We adjust only for factors measured prior to marriage as we want to avoid mediating variables that may be endogenous to the divorce decision. Our data cover two generations, with the younger generation couple the focus of our interest; we control for their characteristics and for those of their parents. In particular, we adjust for whether the parents were divorced or died before husband (wife) reached age 14, the social class of the father of husband (wife), educational attainment of the parents of each spouse, age of the mother at the time of birth of husband (wife), and sibship size of each spouse in the parental family. We also control for a variety of socio-demographic variables that describe the characteristics of husband and wife: year of marriage, husband's age at marriage, the age difference between the spouses, husband's educational attainment in the year of marriage, difference in educational level between the spouses, and whether either member of the couple had a child before marriage, either together or with a different partner. 
The intent of these adjustments is to account for different potential mechanisms in the transmission of birth order effects to divorce risk aside from the socialization experience associated with a birth order position, which is the focus of interest in this undertaking. For example, since only children are more likely to have parents who are divorced (Andersson 1997; Blake 1989), and past studies show evidence for the intergenerational transmission of divorce (e.g., Amato 1996), the onlychild status might be correlated with divorce risk for reasons other than socialization experiences associated with this birth order. We therefore control for whether the parents of husband or wife were divorced before either spouse in the focal couple reached age 14. Similarly, since socioeconomic background is associated with divorce risk (Hoem 1997; Kaplan and Herbst 2015) we adjust for the socioeconomic status of the parents, as well as that of the focal couple. Distributional characteristics of the birth order terms and the other covariates are presented in Appendix Table A1. The effects of these variables on the divorce rate are themselves of interest, and a detailed account is reported in Barclay and Spilerman (2020).

It is important to note that the extant literature is inconsistent in the treatment of "only children," whether as a birth order category or as a family size value (Polit and Falbo 1987). It is, of course, both, but when the two constructs are formulated as sets of categorical variables, for purposes of identification "only child" must be grouped with a second category in one of the constructs and this choice can affect how the results are interpreted (though not the empirical estimates). In this paper, consistent with the formulations of the psychologists and marital counselors that we examine, we consider only-child as a category of birth order.

Fixed effects and selection issues. Much recent research examining the relationship between birth order and a variety of behavioral outcomes has utilized a sibling fixed effects model. This formulation adjusts for time-invariant factors that are shared by siblings, and constitutes an effective way of correcting for unobserved heterogeneity between families. We do not employ a fixed effects 
design for several reasons. First, there is no established way to apply fixed effects to the sibling groups of husband and wife simultaneously, which is necessary since the couple is our unit of analysis. Second, the fixed effects model requires at least two siblings within each family group, which would necessitate the omission of only children, though they constitute a major focus of comment in studies of birth order and divorce (e.g., Blake 1989; Ernst and Angst 1983). ${ }^{1}$ For these reasons, instead of employing a fixed effects design, we rely on a robust set of explanatory variables to account for the heterogeneity across families.

A related matter concerns selection effects. In many European countries there is a complex pattern of movement between the statuses of cohabitation and marriage (Manting 1996; Kiernan 2004), with some tendency for cohabitation to be a precursor to a legal union. In Sweden and other Scandinavian countries, however, possibly because of a long history of cohabitation, there are suggestions that this conjugal status has become normative as an alternative to marriage, with the union often continuing over the life course (Soons, et. al. 2009). Since our analysis is restricted to married couples, it is necessary to examine whether individuals who enter into marriage are different from cohabitators with respect to factors that might influence duration of the union.

We therefore must account for selection into marriage in our examination of the hazard of divorce. The preferred approach is to model the decision to marry versus cohabitate and then take account of this choice in assessing the determinants of divorce. In the present study this proved to not be feasible. Our unit of analysis is the couple, and the Swedish register did not include data on a

\footnotetext{
${ }^{1}$ An added consideration is that the contentions in the popular literature about romantic compatibility tend to assess auspicious and problematic unions separately for each birth order position--e.g. the best and worst pairings for a first born. We emulate this design in our methodological approach, which essentially eliminates the possibility of multiple siblings appearing in the same regression equation.
} 
continuous basis for cohabitating couples, at least not for the bulk of the period under study ${ }^{2}$. Thus, with our focus on compatibility of the partners in a union, we could not model the selection process. ${ }^{3}$

Instead, in our analysis we relied on the fairly rich set of covariates available in the Swedish Register data to reduce the possibly distorting effects of selection. Selection bias is mitigated when the equation predicting divorce incorporates many of the determinants of selection as explanatory factors. We therefore included as potential determinants of divorce a number of variables known to differentiate between marriage and cohabitation statuses: year of birth, age at marriage, educational attainment, sibship size; parental education, SES, and parental divorce experience (Manting 1996; Clarkberg 1999).

Specification of the contentions. An assessment of the validity of claims in a body of work necessarily rests on the accuracy of the operationalization of the assertions. In the writings about birth order and romantic success that we review there are several matters that are unclear in the authors' formulations and require comment.

First, there is the issue of controls. Should the contentions be assessed in the presence or absence of control variables? The argument for evaluating net effects is that the birth order terms will otherwise be biased due to the omission of variates that influence marital success and are correlated with birth order. At the same time, in putting forward their claims the authors were extrapolating from their own clinical experiences, a terrain that is not well suited for taking account

\footnotetext{
${ }^{2}$ The Swedish authorities have collected this information since 2011.

${ }^{3}$ As a fallback we attempted to model selection into marriage versus cohabitation at the individual level. This meant putting aside our focus on compatibility and examining only characteristics of the individual as they influence entrance into one or the other of the conjugal states. To estimate the coefficients we turned to the program DURSEL, written by Boemhke et. al. (2006), which is an adaptation of the Heckman selection approach, applied to duration models. As an exogenous instrument for selection into marriage we used the 1989 legislative reform in Sweden, which created an economic incentive for cohabitating couples to marry and generated a spike in marriages. However, despite several reformulations of our regression model, the program failed to converge.
} 
of correlated factors. Thus, it is not unreasonable to assume that the contentions in the literature about marital success reflect only considerations of birth order (and, in some formulations, gender of the siblings). Rather than dwell on which specification is more appropriate, we estimate the effects both with and without controls.

A second matter concerns the omission of gender by some authors. Both Leeman and Blair formulate contentions of the form, "a first born and a last born often make a very good match" (Blair 2011 , p. 21) without a specification of gender in the pairing of birth orders. Since gender may interact with birth order in determining success of a romantic relationship, we test these contentions by sequentially putting husband, then wife, in the first position of the statement. Specifically, in the above example, when husband is the first born, the relevant observations are the divorce outcomes of first born males, and the comparison is between marriage to a last born wife versus one of a different birth order. Similarly, when the wife is in the first position we compare pairings of a first born wife with a last born husband, versus a husband of a different birth order.

A final issue relates to the notion of birth order in complex family circumstances. A number of psychologists contend that the consequential formulation of birth order is one that takes account of the role in the family that an individual perceives himself or herself to have occupied--what has been termed "psychological birth order" (Campbell, et. al. 1991). Ordinal birth order does not take account of the spacing between sibling births or the entanglements of blended families in which children from different parental unions are mixed. While the second of these concerns challenges the very meaning of birth order position, we have effectively disposed of this problem by excluding couples where either husband or wife has a half-sibling.

The fact of long durations between sibling births remains a concern since the linkage between birth order and personality--the presumed mechanism in accounting for birth order effects in romantic settings--might well be affected. A middle child, for example, might adopt the coping style of a last 
born if there is a long interval to the next sibling. We addressed this issue by replicating the analyses with couples dropped from the study if either husband or wife came from a sibship with a separation of five or more years between any two births. In practice, this improvement in conceptual clarity must be balanced against the sample lossage, which is considerable, often exceeding 50\%. For this reason, and because we wish to maintain comparability with previous empirical research which has consistently used the ordinal measure, we report our findings with the ordinal specification of birth order but indicate how the results are modified when the psychological measure is employed.

\section{EVALUATION OF LEEMAN AND BLAIR}

The assertions of the four psychologists and marital counselors can be divided into two categories. The contentions of Leeman and Blair are based solely on the pairings of birth orders while the formulations of Cane and Toman are more elaborate, adding a consideration of sibling gender to birth order. It is efficient to examine the two sets of claims separately and in this section we focus on the former.

Leemans's (2009) contentions have the following flavor: "Firstborn plus lastborn equals bliss (usually)" (p. 220), with the qualification intended to intimate that other factors besides birth order may be at play in a good match. Similarly, "Lastborn plus lastborn equals chaos" (p. 227). Leeman's set of contentions is summarized in Panel A of Table 1. Out of a possible 16 pairings of only child (OC), first born (FB), middle born (MB), and last born (LB) among spouses, Leeman makes ten claims about the consequences of particular unions; six predict to favorable outcomes (labeled G), four to infelicitous couplings (labeled B). In particular, Leeman considers a pairing in which the partners have the same birth order to have a poor prognosis, ${ }^{4}$ while a pairing of last born with a

\footnotetext{
${ }^{4}$ See Hartshorne et. al. (2009), incidentally, for precisely the opposite contention about partners of the same birth order.
} 
partner of a different birth order augers well for marital bliss. In support of his claims, Leeman cites studies by Toman (1976) and Kemper (1966).

Table 1 about here

We base our test of Leeman's contentions on an examination of the divorce rates in the 16 pairings. Specifically, we introduced separate dummy terms for each of the ten designated pairings, with the remaining couplings, for which birth order is presumably less consequential, constituting the reference term. Thus, a finding that all, or most, of the propitious pairings have lower rates of divorce than the reference category, and that all or most of the infelicitous pairings have higher divorce rates than the reference term would support Leeman's claims.

In Table 2 we report our results. Panel A summarizes the findings without controls; Panel B shows the findings with controls. In each panel, the left matrix conveys the results with husband in the first birth order position in a Leeman contention (row entries), while the right side matrix shows the findings with wife in the first position. Consistent with the perspective that a pairing should be evaluated in terms of the outcomes associated with others of the same birth order, each row derives from a separate regression using the subset of respondents with the same index birth order. The nonzero entries indicate outcomes from a coupling emphasized by Leeman while the zeros denote the reference term. Note that the contrast is different for the last row. In rows 1-3, the contrast is with the set of undistinguished pairings, while in the last row, where all pairings are either auspicious or precarious, the sole problematic coupling $(\mathrm{LB} \times \mathrm{LB})$ is the reference term. The entries in the matrices are (non-exponentiated) hazard coefficients; thus a negative value suggests a lower divorce rate than the reference coupling--a favorable outcome, while a positive entry indicates a higher divorce rate.

${ }^{5}$ Leeman's (2009, p. 336) citation is to "Kempler," but the intended author clearly is Theodore D. Kemper. 
Table 2 about here

Looking first at the results without controls (Panel A), Leeman's contentions find little support. Of the nine entries in each of the two matrices there is only one significant coefficient, and while it refers to a presumably "bad" pairing the negative sign suggests a better marital outcome than for the reference category. Even if we ignore the significance of the coefficients and focus on the pattern of the signs, in the view that Leeman's contentions might be correct but the effects for individual pairings are weak, we fail to find support. When the pairings are based on husband's birth order, four of the contrasts are consistent with Leeman; five are not. When the pairings reflect wife's birth order, four of the nine contrasts fail to support his claims.

When controls are introduced our assessment is little changed. With the pairings reflecting husband's birth order, two of the coefficients are significant and support Leeman; the pattern of signs, however, shows only four of the nine comparisons consistent with his contentions. When the selection is on wife's birth order, the results are marginally improved: six of the nine comparison have signs consistent with Leeman, though this outcome is not statistically different from chance. ${ }^{6}$ In summary, we find no evidence from any of the formulations that the pattern of results departs from chance outcomes.

This assessment is confirmed by the summary tests reported at the bottom of Panels A and B. This test utilizes the full sample and hence there is one test in each panel. "Good" is a dummy term for the aggregation of all of Leeman's auspicious pairings and "Bad" is a term for all his problematic

\footnotetext{
${ }^{6} \mathrm{~A}$ test of the hypothesis that Leeman's contentions do no better than random outcomes, based on the probability of six or more successes in nine Bernoulli trials with success probability $\mathrm{p}=.5$, cannot be rejected at the .05 level.
} 
pairings. Neither of the tests suggests a significant effect relative to the unremarked pairings, the reference term.

What about Blair (2011)? Her claims about birth order and romantic success are more extensive than Leeman's in that she has a prognosis for every pairing. But what support can be gleaned with the Swedish register data for her contentions?

Blair's claims are summarized in Panel B of Table 1. We formulate the analysis of her contentions in a manner similar to Leeman's, though there are a few differences. First, in the rows for MB and LB, since there are no undistinguished pairings, we take the sole pairing in each row with a poor prognosis as the reference category. More consequential, in the rows for OC and FB where there are multiple cells of desirable and problematic pairings, we arbitrarily select the main diagonal term as the reference category, then assess the presumably good pairings against this problematic union. These are the results reported in Table 3. The analysis was then repeated with the alternative problematic union serving as the reference term.

Table 3 about here

Turning first to the results without controls (Panel A), the last two matrix rows show only one entry from among twelve in the two matrices that supports Blair's claims; the other off-diagonal terms predict to poor marital outcomes (positive coefficient) though, in Blair's formulation, the cells represent auspicious pairings. Moreover, four of the coefficients are significant. While the results in the first two rows are more supportive of Blair, an assessment of the totality of her contentions, represented by the full matrix of outcomes, shows little evidence of a departure from chance results. Further, this assessment persists when the analysis is repeated with the alternative "bad" pairing taken as the reference term (not shown). 
The results are not improved when the controls are introduced (Panel B). Turning to the last two matrix rows, five of the six entries in one matrix and four of the six in the other have signs signifying poorer marital outcomes than the reference categories, though the former represent Blair's predictions for marital success. While the results in the first two rows are, again, more favorable to Blair, the full array of matrix coefficients does not show evidence of a systematic pattern of support for her contentions.

This appraisal is reinforced by the summary tests reported at the bottom of each panel. In neither the case of no controls, nor with controls present, is the contrast between the pooled desirable pairings significantly different from the pooled problematic pairings, the latter serving as the reference term. In summary, with respect to both Leeman and Blair, their lists of propitious and precarious marital pairings appear to differ in outcome only randomly from the reference categories.

\section{EVALUATION OF CANE AND TOMAN}

The contentions of Cane and Toman are more nuanced in that each takes account of the gender composition of the sibship as well birth order. Turning first to Cane, a typical proposition, referring to an older brother of brothers Cane (2008, p. 14), claims that "the best match [for him] is a younger sister of brothers." Later: "Another potential match is a younger sister of sisters." Cane motivates his predictions in terms of role acquisition as a child; for example, "[t]he younger sister of brothers feels a mutual attraction to the extent that she unconsciously yearns for a boy who can lead like the older brother of brothers," thus replicating familiarities in her origin household.

Our formulation of Cane's contentions is presented in Panel A of Table 4. In each row, the index ID is exterior to the parentheses, while the sibship composition is conveyed by the terms within the parentheses. Thus, in row 1, the index ID is an older brother of brothers. The best pairing is either with a younger sister of brothers or a younger sister of sisters, while the worst is with an older sister of brothers. Cane sometimes proposes additional pairings as propitious or problematic, but 
these usually are qualified in some way--e.g. "A female only child might be a good match, especially if her mother had one or more older brothers" (Cane 2008, p. 14). Because of their contingent nature, which would be difficult to model with our data, we disregard these claims in our listing of good and poor unions.

Table 4 about here

Cane is generally mute on further details of the sibship composition, such as whether it is gender mixed or not, or the size of the sibship. We have formulated his contentions in a narrow way, as requiring siblings of a single gender; thus, the symbol (b..b) means any number of brothers in the sibship, but no sisters. This might be more restrictive than Cane intended, but lacking guidance on the matter we have constructed the categories to encompass the combinations that he certainly intended.

Our analytic strategy is to subset the data by the index ID configuration, then compare the outcomes for "best" and "worst" pairings for this ID with the reference term consisting of the remaining matches available to the ID. Thus, referring to row one, the data subset consists of all married males with younger brothers, and dummy terms are introduced for the best and worst matches, with all other pairings constituting the reference term. With this approach, the marital longevity of each index ID is assessed only in terms of the pairing outcomes of others with the same birth order and sibship configuration. Again, not knowing whether Cane was contemplating zeroorder effects or effects net of the controls, we report results for both formulations.

The findings from these analyses, reported in Panel B, provide little support for Cane. In the "no controls" section, among the 20 entries for best and worst matches, 14 corroborate his 
contentions though only one term is significant. ${ }^{7}$ In the runs with controls, the results are hardly better-- 8 of the 20 entries do not support Cane. In summary, we find little basis to suggest that couples matched in accordance with Cane's formulation of auspicious and problematic unions fare differently from the reference category of undistinguished unions.

The most influential student of birth order effects in romantic settings is Walter Toman (1961). Moreover, he is the sole scholar to have formulated a theoretical argument as to why particular birth order pairings can be conducive to, or detract from, marital success. Toman's thesis, drawing from the work of Alfred Adler (1928; 1937), is that birth order imparts a particular coping style, a result of learning to navigate among older and younger siblings who are pursuing their own goals. These acquired skills are then brought into the marriage and prove efficacious for equanimity in the union when the styles of husband and wife complement one another. Toman uses the terms "duplication" and "complementarity" to designate the desired matching of birth order and sibship composition between the partners.

Toman's contentions about best and worst pairings are summarized in Panel A of Table 5. Toman's list of "best" clearly anticipates the assessments of Cane, some 50 years later. Almost all are identical to one of the two unions in Panel A of Table 4 that Cane considers propitious, and there is overlap as well in their lists of inauspicious pairings. Clearly, Cane's contention set is derived from Toman's. While we failed to find support for Cane's predictions, we nonetheless examine Toman's contentions because his more concise list might have predictive value. Our analytic approach is identical to that in the Cane assessment and our findings are reported in Panel B of Table 5.

\section{Table 5 about here}

\footnotetext{
${ }^{7} \mathrm{~A}$ Binomial test of 14 or more successes in 20 trials with success probability $=.5$ fails to reject the hypothesis of chance outcomes at the .05 level.
} 
Despite the allure of Toman's thesis about duplication and complementarity, our analysis finds no evidence to support his claims. In the "no controls" section of Panel B, only two terms are significant and in both cases the sign is opposite Toman's prediction. Similarly, the distribution of coefficient signs does not display a pattern that is supportive of Toman. Moreover, when controls are introduced his contentions fare no better.

The preceding formulations of birth order effects in romantic settings pretty much span the popular literature on the topic. Our assessment of the predictions in this body of work, about auspicious and problematic pairings, is consistent across the various formulations: in no case do they differ in a systematic way from the reference category, which generally consists of unremarked pairings for which birth order, presumably, has little impact on marital success. Nonetheless, we cannot conclude from this evaluation that the pairing of birth orders truly has no impact on marital longevity, only that the contentions that appear in the popular literature have little predictive value.

\section{A NEW ANALYSIS OF BIRTH ORDER EFFECTS ON MARITAL SUCCESS}

Does birth order matter for marital bliss? Other than Toman's formulation of the duplication and complementarity principle, we lack a theory of birth order effects in romantic relationships to guide an empirical examination. In this circumstance, our approach to assessing the consequences of birth order pairings is to undertake an analysis of divorce outcomes in the variety of pairing combinations and seek meaningful patterns in the outcomes. Moreover, lacking theoretical guidance, we refrain from attributing meaning to what appear to be isolated effects, even when statistically significant. It is interpretable patterns of findings that we seek.

Since birth order is associated with particular cognitive and non-cognitive features (e.g. Conley and Glauber 2006; Black et. al. 2017; Barclay et. al. 2017) which may influence marital satisfaction, and since gender of birth order position in a pairing may well be consequential, we 
subset the data by both husband's birth order and by wife's. In essence, a separate regression is run for each birth order of each spouse, with regressors for the possible marital choices of the index birth position, and union with an only child serving as the reference term. Further, at this point, we no longer need to take account of the analytic limitations of the clinical practitioners; rather, consistent with the research literature we restrict the analysis to pairing effects net of the controls. These are the outcomes we now examine.

In Table 6 we report results by husband's birth order (Panel A) and by wife's (Panel B). Turning first to husband's pairing choices, there are a number of significant entries. Since the terms in each row constitute effects relative to an OC partner, we can assert that irrespective of the birth order of husband he does best when coupled with a mate who is not an only child (negative entries throughout the table). This assessment holds true even when husband is himself an only child--OC X $\mathrm{OC}$ is the poorest of the parings available to him.

Table 6 about here

A second pattern emerges from a comparison of husband's partnering with a FB or MB wife versus a LB wife. The former choices consistently dominate LB in terms of protection from divorce in that an LB is never the most protective option. This assessment is based on a comparison of coefficient magnitudes with, for the moment, issues of statistical significance ignored. In short, it appears that marriage with a last born may be a poor choice for a male of any birth order.

Turning to wife's selections in Panel B, aside from a tendency to uniformly poor outcomes when paired with a husband who is an only child (negative entries in 11/12 comparisons), there is little in the way of an evident pattern. For an OC or FB wife, the birth order of husband appears to have little impact on marital longevity. The findings for MB and LB wives are stronger, and can be 
interpreted as suggesting that pairing with a LB husband is a poor choice, but we are loathe to attribute substantive meaning to a regularity that is based on so few entries.

To uncover patterns that are convincing, it is vital to have a large number of data points for examination. A data point in the current investigation is a pairing effect, and the availability of 16 pairing effects in each of the matrices of Table 6 can only be suggestive, hardly sufficient to convincingly establish the presence of a pattern. There is an additional problem with making inferences about birth order effects from these matrices: while sibship size is controlled, the smaller sibships are greatly overrepresented in the data because they are far more common in the population. Thus, it is conceivable that the effects noted in the matrices of Table 6 hold for sibship sizes 2 and 3 , but not for larger sibships. In short, the findings might be particular to combinations of small families, not universal birth order effects.

Birth order within family size. With the very large data set at our disposal we can expand the number of pairings available for analysis and also address the issue of dominance of small sibships in the data. In particular, in Table 7 the matrices of pairing effects have been unfurled so that the observational unit is now "birth order within family size". We limit family size to 5, the maximum from which reliable pairing effects can be gleaned with the Swedish population data; larger sibships are merged with size 5. The estimation is now based on subsets for each index birth order within family size category. Again, each matrix row derives from a separate regression, with effects reported for pairings with spouse's birth order within family size, and the reference term denoting the pairing with an only child. Panel A reports the spousal selections of husband; Panel B reflects the selections of wife.

Table 7 about here 
Our objective with these matrices is to examine the consistency of birth order effects across the various family size combinations. Thus, the entries should be thought of as data points for further study rather than as effects to be individually interpreted. In order to discern patterns we give equal weight to all entries irrespective of the N's underlying the estimates. Thus, the fact that entries from the pairings of large sibships are based on smaller N's than pairings of small sibships is not a matter of consequence; our interest is in ascertaining whether there are birth order effects that replicate across the different sibship size combinations, not in estimating summary effects in the population. Further, to identify patterns we examine the sign of the difference between entries of interest, then employ a binomial test of significance based on the likelihood that the proportion of positive, or negative, effects in the proposed pattern could arise from chance alone.

The results for husband (Panel A) largely support the tentative assessments made from Table 6. First, irrespective of husband's birth order, marriage to an $\mathrm{OC}$ wife consistently generates a higher divorce rate than any other spousal pairing. Out of 132 comparisons between marriage with a nonOC versus an OC wife (the $1 / 1$ column) the pairing with a non-OC wife does better in 113 instances (negative coefficient, green shading). A binomial test of this effect, posed as the likelihood of 113 or more successes in 132 trials with $\mathrm{p}=.5$ is highly significant,

$$
\mathrm{B}(\mathrm{X}>=113 ; \mathrm{N}=132, \mathrm{p}=.5)<.0001 \text {, }
$$

making evident the precariousness of partnering with an only child. Moreover, there is a suggestion that an OC x OC union is even more predictive of divorce than an OC x non-OC pairing; this is the case in 9/11 comparisons (row 1).

A similar assessment is reached with respect to wife's selections (Panel B), though the effects are somewhat weaker. For wife, there are 99/132 pairings in which marriage with a non-OC husband 
predicts to a lower divorce rate than coupling with an OC spouse. The comparable binomial test is highly significant:

$$
\mathrm{B}(\mathrm{X}>=99 ; \mathrm{N}=132, \mathrm{p}=.5)<.0001 \text {. }
$$

And, again, the partnering of $\mathrm{OC}$ with $\mathrm{OC}$ does poorer with respect to marriage longevity than the pairing of an OC wife with a husband of a different birth order (9/11 instances). The bottom line is that marriage to an only child is a dicey undertaking, for both men and for women. ${ }^{8}$

The Table 8 entries are identical to those in Table 7 but the highlighting now emphasizes the effects of birth order position. For males, one evident pattern, depicted in Panel A, concerns the difference in divorce proclivity from marriage to a first born versus a last born wife. A simple count of outcomes shows 30/48 instances in which a first born wife provides the greater protection (green shading); in comparison, there are only 5 instances in which a last born wife is more preventive of divorce (red shading). The comparisons here are between first born and last born wives within the four sibship size categories of wife. Middle born wives appear to be intermediate. In the three size groupings in which there is a middle born, this status is most protective in 13/36 instances, versus 22/36 for first borns and 1/36 for last borns.

Table 8 about here

A statistical test of these effects, comparing the outcome of marriage to a FB wife vs. a nonFB wife,

$$
\mathrm{B}(\mathrm{X}>=30 ; \mathrm{N}=48, \mathrm{P}=.3750)<.001,
$$

\footnotetext{
${ }^{8}$ There is some erosion in stability of the results for family sizes 4 and $5+$, which is especially evident for wife's choices (Panel B). This is likely a result of the decline in sample size for large families.
} 
is highly significant. Here, $\mathrm{p}=.375$ is the average of $\mathrm{P}=.5$ for the 12 cases of family size 2 (where there are two birth order selections) and $\mathrm{p}=.334$ for the 36 instances of larger family sizes, where there are three selections.

If first born wives are most protective whatever husband's birth order, it is also the case that marriage to a last born wife is singularly associated with divorce risk. A test of this assertion is based on a comparison between the outcomes of marriage to a MB versus a LB wife. There are 36 cases for comparison, with MB more protective in 26 instances. Thus,

$$
\mathrm{B}(\mathrm{X}>=26 ; \mathrm{N}=36, \mathrm{p}=.5)<.01
$$

and we conclude that a LB wife affords the least protection.

The consequences of spouse's birth order for the pairing decisions of women (Panel B) are more complex, and there is some evidence of an interaction with sibship size. A first born or last born husband makes little difference for marriage stability when the husband comes from sibship sizes 2 or 3-first born husband is most protective in 9 comparisons, last born in 10 (and middle born in 5). In partnering with a husband from a larger sibship the story is different: first born husband is most protective in 14 comparisons, last born in 5 (and middle born in 5). While it may be the case that in small sibship households birth order effects are associated with a different development process than in large sibships, in the absence of theory to support such an assertion we refrain from attributing substantive meaning to the finding. Instead, we conclude that in women's pairing decisions there is little evidence that the birth order of spouse matters in a systematic way for marital success (other than the only child/non-only child dichotomy).

The preceding findings are summarized by the graphs in Figure 1, which were constructed from a hazard regression with additive terms for birth order within family size. The red curve conveys the import of husband's selections; the green gives wife's choices. The effects here are 
hazard ratios, with the selection of an OC partner serving as the reference term for each curve; hence, the more negative the entry the greater the protection against divorce. The graphs effectively convey the principal findings we have reported: (a) for both husband and wife a non-OC spouse is preferable to pairing with OC; (b) for husband there is a clear tendency for a first born wife to be most protective and a last born wife least protective. And, (c) there is no evident pattern in marital compatibility that is revealed by the choices of wife.

Figure 1 about here

We conclude with estimates of the magnitude of the effects, net of the controls. A calculation of hazard ratios for different combinations of OC and non-OC pairings, relative to a pairing of nonOCs, reveals the following. For a non-OC husband, marriage with an $\mathrm{OC}$ wife translates into a divorce rate that is $10 \%$ higher than the reference category while the partnering of a non-OC wife with an OC husband results in a 7\% higher rate. Most notable, the coupling of two OCs yields a divorce rate that is $15 \%$ higher than the pairing of two non-OCs--an effect that is considerable.

Similar estimates of the consequences of other mate selections by husband were calculated from a regression with dummy terms for wife's birth order and the controls. For husband, marriage to an LB wife generates a divorce rate that is $93 \%$ of the rate for marriage to an OC wife, with the rate declining to $89 \%$ when the wife is first born, making evident the protective value of a first born wife over a last born. Though less pronounced than the OC/non-OC contrast, these effects are not negligible.

To summarize our findings, there is clear evidence that birth order is consequential for marital compatibility. A universal finding is that a union with an only child is detrimental to marriage longevity, irrespective of spouse's birth order. Aside from this result, birth order appears to matter 
only in husband's choices, with his best chance for bliss, or at least contentment, linked to marriage with a first born wife, and his poorest with a last born wife.

Psychological birth order. How are our findings modified if psychological birth order--an individual's perception of position within the family--is used in place of the ordinal measure? The attractiveness of psychological birth order is that it more closely aligns with developmental processes in the origin household that are presumed to be responsible for the birth order effects. A recognition that the complexities of family arrangements can make the ordinal measure a poor proxy for the life experiences associated with a birth order position dates to the writings of Alfred Adler (1937). It has remained a persistent theme in the formulations of psychologists (e.g. Eckstein, et. al. 2010; Campbell et. al. 1991; Ashby et. al. 2003), culminating in the construction of the White-Campbell Psychological Birth Order Inventory (Campbell, et. al. 1991), which was intended to better match empirical research with the theoretical concept of birth order.

While the PBOI scale has been used in small empirical studies (e.g. Pilkington, et. al. 1997; Campbell, et. al. 1991) it is not suitable for large extant data sets such as population register data, since the particular items required by the scale are generally not available in the data sets. In the present investigation we sought to eliminate the sorts of family complexities that might compromise the alignment of ordinal birth order with the theoretical concept by limiting the study to couples in which neither spouse had a half-sibling.

Further, we carried out a sensitivity analysis to one additional factor that might disrupt the alignment of ordinal birth order with the theoretical concept--duration between sibling births. As noted previously, a large gap between sibling births could mean that the earlier child spent much of his or her young life as an only child or a last born, and may have internalized aspects of the coping style associated with that birth order position, even after the birth of the later sibling. To reduce this 
noise in our data, we replicated the analysis, deleting couples in which either spouse came from a sibship with a gap of 5 or more years between adjacent births.

This deletion resulted in a reduction in sample size from 235,208 to 110,118 . The lossage was particularly severe for large sibships, with the consequence that it was not possible to obtain stable estimates for the disaggregated models of Tables 7 and 8 . We were able, however, to replicate our evaluation of the contentions of the four psychologists, with the conclusion that in no case would our assessment be altered. In general, there are fewer significant entries in the modified tables because of the fall off in sample size. We were also able to replicate Table 6; again with the finding that, for husband, the poorest choice is a last born spouse, while, for wife, there is no discernible advantage from pairing with any particular birth order of husband. ${ }^{9}$ In summary, the results we have reported are robust with respect to the spacing between sibship births.

\section{DISCUSSION}

How can we understand these findings? The problematics of marriage with an only child has long been suspected. Only children are viewed as selfish, anxious, socially inept, narcissistic, and maladjusted; moreover, some empirical studies, though with small samples, have found support for these assertions (e.g, Polit and Falbo 1987; Cai et. al. 2011; Cameron, et. al. 2011). The most common conceptual formulation for explaining the purported characteristics of the only child is the siblings-as-resource model which posits that children learn interpersonal skills from the presence of brothers and sisters, and that these coping strategies are drawn upon in peer relationships throughout the life course (Downey and Condron 2004, p. 334; also see MacKinnon et. al. 1997; Brody 1998). The failure of an only child to acquire critical interaction skills might well detract from the prospects

\footnotetext{
${ }^{9}$ The tables with this formulation of psychological birth order are available from the authors.
} 
of a lasting marriage, since negotiation and compromise would appear to be essential to a harmonious union.

Blake (1989, p. 101) and Ernst and Angst (1983, p. 271) point out that only children are more likely than children raised with siblings to issue from homes where there was a parental divorce. This suggests a second mechanism for explaining their lesser success in marriage, namely that the higher divorce rate associated with offspring from divorced households (Corak 2001; Amato 1996; Mueller and Pope 1977; Webster, et. al. 1995)--essentially an intergenerational transmission of divorce--would apply disproportionately to only children. While our data do not permit an exploration of the alternative mechanisms that might be responsible for the heightened divorce proclivity of only children, we have documented the universality of the effect in the sense that it appears to not be contingent upon spouse's birth order though the effect is more pronounced when both are only children.

If there has been suspicion about the fragility of marriage to an only child, much less has been written about the possible protective effects for men of coupling with a first born wife; alternatively, the heightened vulnerability to divorce associated with marriage to a last born wife. There are suggestions in the literature consistent with this finding, but not fully developed theories. The essential argument is that a first born female is likely to have nurtured and cared for younger siblings, has internalized this supportive role and can fall back upon the skill set when efficacious in later relationships (Schuitemaker and Enthoven 2016, p. 67; Leeman 2009, p.221). In terms of empirical support, Badger and Reddy (2009) argue that first borns score high on emotional stability and willingness to assume responsibility, and Sulloway (1996) contends that they are likely to have served as surrogate parents. While those studies did not distinguish between the genders of the first borns, other research emphasizes the greater association of nurturance with females (e.g., Pollet and 
Nettle 2007; Kammeyer 1966). Nonetheless, although this literature may be suggestive of the protective effects of a first born wife, it is hardly definitive.

Finally, it must be noted that aside from our tests of the marital counselors' contentions, the present study was essentially an inductive undertaking, a pattern recognition exploration. While we were conservative in attributing significance to associations in the data between birth order and divorce propensity, an inductive approach is inherently more suited to uncovering propositions than to testing them. This makes imperative the replication of this study with data from another country, preferably one similar in tradition and population composition.

In principle, our findings should replicate in very different cultural settings, so long as monogamy is the norm and divorce can be initiated by either member of a couple. Marital satisfaction would appear to be intrinsic to the quality of a relationship rather than culturally determined, and it is difficult to conceive of societal constraints on marital dissolution that take account of birth order. Moreover, the theory which undergirds our study--Adlerian theory about the linkage of coping style with birth order--purports to be universal in its applicability, in that it rests upon the interactions among siblings in early childhood, a period likely to be more conditioned by developmental processes than cultural norms. Nonetheless, rather than rely upon claims of universality in the selection of a site for replication, a cautious approach would be to first examine our findings with data from another Scandinavian country.

\section{CONCLUSIONS}

We began this paper with a consideration of the claims regarding birth order pairings and marital success that appear in the popular literature. Our assessment is that the contentions of the most cited authors concerning auspicious and problematic pairings have little basis in fact, despite the 
wide acceptance of their views. Indeed, the popularity of this literature, in the face of minimal empirical support, is, itself, a matter of interest.

For many individuals the literature on birth order and romantic compatibility serves a useful function. It permits a complex process that is governed by a myriad of considerations to be reduced to a few simple--perhaps simplistic--factors that are easily comprehended and measured. In this sense, the contentions about romantic success are not very distant from recommendations in the "selfhelp" literatures--e.g., ten steps to achieving happiness; to influencing people--or even from astrological forecasts about future life events based on one's birth date (in which, incidentally, romantic success has been discussed in terms of the zodiac charts of partners (e.g. White 2012)). All these nostrums promise insight into the complexities of life processes based on a very few graspable considerations, permitting one to believe that destiny can be influenced from esoteric knowledge.

In fairness to the authors whose formulations we have examined, all make clear that many other factors besides birth order are at play in making for a successful romance or marriage; yet, as the book titles make clear, the focus of their writings is on the consequences of birth order, not on the other factors. In securing a readership, all are aided by the fact that birth order effects are an established matter with respect to cognitive outcomes and, further, Alfred Adler's theory about the linkage of birth order to coping style is a well regarded formulation. Thus, the extension of birth order claims to encompass pairing effects in romantic relationships was not, perhaps, a distant step.

Nonetheless, the contentions in this literature, however engaging and plausible on the surface, are not backed by empirical research. In our study we do find that birth order matters, but it is additive effects that count, not the consequences of pairing, and even here only in the limited case of husband's choice of wife. The sole exception to this assessment concerns the only child, for whom marriage with another only has a notable detrimental impact on longevity of the union. 


\section{REFERENCES}

Adams, B. N. 1972. "Birth order: A critical review." Sociometry 35, 411-439.

Adler Alfred. 1928. "Characteristics of the first, second and third child". Children 3(5):14-52.

Adler, Alfred. 1937. "How position in family influences life style" International Journal of Individual Psychology, 3, pp. 211-227.

Amato, P.R. 1996. Explaining the Intergenerational Transmission of Divorce. Journal of Marriage and the Family 58(3): 628-640.

Andersson, G. (1997). "The impact of children on divorce risks of Swedish women." European Journal of Population 13(2), 109-145.

Ashby, Jeffrey S., Kenneth A. LoCicero, and Marry C. Kenny. 2003. "The Relationship of Multidimensional Perfectionism to Psychological Birth Order." Journal of Individual Psychology. Spring 2003, 59(1), pp. 42-51.

Badger, J., \& Reddy, P. 2009. "The effects of birth order on personality traits and feelings of academic sibling rivalry." Psychology Teaching Review, 15(1), pp. 45-54.

Barclay, Kieron and Seymour Spilerman. 2020. "Birth order and divorce risk." Submitted for publication.

Barclay, Kieron J. 2015. "A within-family analysis of birth order and intelligence using population conscription data on Swedish men." Intelligence 49, pp. 134-43.

Barclay, Kieron J., Martin Hallsten, and Mikko Myrskyla. 2017. "Birth Order and College Major in Sweden." Social Forces, 96(2), pp. 629-660.

Belmont L and Marolla FA. 1973. "Birth order, family size and intelligence." Science 182:1096-1101.

Birtchnell, J. \& Mayhew, J. 1977. "Toman's theory: Tested for mate selection and friendship formation." Journal of Individual Psychology, 33, pp. 18-36.

Bjerkedal T, Kristensen P, Skjeret GA, Brevik JI. 2007. "Intelligence test scores and birth order among young Norwegian men (conscripts) analyzed within and between families." Intelligence 35(6):526-541.

Black, S. E., Devereux, P. J. and Salvanes, K. G. 2005, "The more the merrier? The effect of family size and birth order on children's education." Quarterly Journal of Economics 120(2), 669-700.

Black, S. E., Devereux, P. J. and Salvanes, K. G. 2011, "Older and wiser? Birth order and IQ of young men", CESifo Economic Studies 57(1), 103-120.

Black, Sandra E., Eric Gronqvist, and Bjorn Ockert. 2017. "Born to Lead? The Effect of Birth Order on NonCognitive Abilities." Working Paper \#23393, National Bureau of Economic Research.

Blair, Linda. 2011. Birth Order: What your position in the family really tells you about your character. London: Piatkus. 
Blake, Judith. 1989. Family Size and Achievement. Berkeley: University of California Press.

Bleske-Rechek A, Kelley JA. 2014. "Birth order and personality: A within-family test using independent selfreports from both firstborn and laterborn siblings." Personality and Individual Differences 56, pp. 1518.

Bloser, Edward Charles. 1993. "The Relationship between Marital Adjustment and Sibling Constellation." Research/Technical Report 143. U.S. Dept. of Education. ERIC.

Breland H.M. 1974. "Birth order, family configuration, and verbal achievement." Child Development, 45(4):1011-1019.

Brody, G.H. 1998. "Sibling relationship quality: Its causes and consequences." Annual Review of Psychology, 49 , pp. $1-24$

Business Insider. 2017. "Who you should marry based on your birth order."

https://www.businessinsider.com/who-you-should-marry-birth-order-2017-1.

Cai, H., Kwan, V. S. Y., \& Sedikides, C. 2012. "A socio-cultural approach to narcissism: The case of modern China." European Journal of Personality, 26, 529-535.

Cameron, Lisa, Nisvan Erkal, Lata Gangadharan, and Xin Meng. 2013. "Little emperors: Behavioral impacts of China's one-child policy," Science, 339, pp. 953-957.

Campbell, L., White, J., \& Stewart, A. 1991. "The relationship of psychological birth order to actual birth order." Individual Psychology: Journal of Adlerian Theory, Research \& Practice, 47(3), pp. 380-391.

Cane, William. 2008. The birth order book of love. Philadelphia: Da Capo Press.

CBSnews. 2011. "Does birth order make or break a relationship?" https://www.cbsnews.com/news/does-birthorder-make-or-break-a-relationship/.

Clarkberg, Marin. 1999. "The Price of Partnering: The Role of Economic Well-Being in Young Adults' First Union Experiences." Social Forces 77:945-68.

Conley, Dalton and Rebecca Glauber 2006. "Parental Educational Investment and Children's Academic Risk." Journal of Human Resources, 41(4), pp.722-37.

Conley, Dalton. 2004. The Pecking Order: Which Siblings Succeed and Why. New York: NY: Pantheon Books.

Corak, Miles. 2001. " The Long-Term Consequences of Parental Loss on Adolescents," Journal of Labor Economics, 19(3), pp. 682-715.

Damian RI, Roberts BW. 2015. "The associations of birth order with personality and intelligence in a representative sample of US high school students." Journal of Research in Personality, 58, pp. 96-105.

Downey, Douglas B. and Dennis J. Condron. 2004. "Playing Well with Others in Kindergarten: The Benefit of Siblings at Home," Journal of Marriage and Family, 66(2), pp. 333-350. 
Eckstein Daniel, Kristen J. Aycock, Mark A. Sperber, John McDonald, Victor Van Wiesner III, Richard E. Watts, and Phil Ginsburg. 2010. "A Review of 200 Birth-Order Studies: Lifestyle Characteristic," The journal of Individual Psychology, 66(4), pp. 408-434.

Ernst, C, \& Angst, J. (1983). Birth order: Its influence on personality. Berlin, Germany: Springer Verlag.

Focus on the Family. 2015. "How birth order affects your marriage." https://www.focusonthefamily.com/marrige/communication-and-conflict/how-birth-order-affectsyour-marriage.

Forer, L. K. 1969. Birth order and life roles. Springfield, Illinois: Charles C. Thomas.

Freese, Jeremy, Brian Powell, and Lala C. Steelman. 1999. "Rebel without a cause or effect: Birth order and social attitudes." American Sociological Review, 64(2), pp. 207-231.

Galton 1874. English men of science. London: Macmillan

Gold, S. B., \& Dobson, J. E. 1988. "Birth order, marital quality, and stability: a path analysis of Toman's theory." Journal of Individual Psychology, 44, 355-364.

Härkönen, J. (2014). "Divorce: Trends, patterns, causes, consequences", In J. K. Treas, J. Scott \& M. Richards, eds., The Wiley-Blackwell Companion to the Sociology of Families. John Wiley \& Sons, Chichester, pp. 303-322.

Hartshorne, Joshua K., Nancy Salem-Hartshorne, and Timothy S. Hartshorne. 2009. "Birth order effects in the formation of long-term relationships." Journal of Individual Psychology, 65, pp. 156-176.

Hoem, J. M. (1997). "Educational gradients in divorce risks in Sweden in recent decades." Population Studies 51(1), 19-27.

Huffington Post. 2017. "What your birth order can tell you about your love life." https://www.huffpost.com/.../what-your-birth-order-can-tell-you-about-your-love-life...

Isaacson, Cliff and Meg Schneider. 2004. The Birth Order Effect for Couples: How Birth Order Affects Your Relationships - And What You Can Do About It. Glouster: Fair Winds Press.

Jefferson Jr., Tyrone, Jeffrey H. Herbst, and Robert R. McCrae. 1998. "Associations between Birth Order and Personality Traits: Evidence from Self-Reports and Observer Ratings." Journal of Research in Personality 32 , pp. 498-509.

Kammeyer, Kenneth. 1966. " Birth Order and the Feminine Sex Role Among College Women." American Sociological Review, 31(4), pp. 508-515

Kantarevic, J. and Mechoulan, S. (2006), 'Birth order, educational attainment, and earnings: An investigation using the PSID', Journal of Human Resources 41(4), 755-777.

Kaplan Amit and Anat Herbst. 2015. "Stratified Patterns of Divorce: Earnings, Education, and Gender." Demographic Research 32, pp. 949-82.

Kemper, Theodore D. 1966 "Mate selection and marital satisfaction according to sibling type of husband and wife." Journal of Marriage and the Family 28:346-349. 
Kiernan, K. (2004). "Unmarried Cohabitation and Parenthood in Britain and Europe." Law \& Policy 26(1): 33 55.

Leeman, Kevin. 2009. The Birth Order Book: Why You Are the Way You Are. Grand Rapids: Revell.

Lyngstad, T. H. \& Jalovaara. M. (2010), "A review of the antecedents of union dissolution." Demographic Research 23(10), 257-292.

MacKinnon, L. C., Starnes, R., Volling, B., \& Johnson, S. 1997. "Perceptions of parting as predictors of boys' sibling and peer relations." Developmental Psychology, 33, pp. 1024-1031.

Manting, D. (1996) "The changing meaning of cohabitation", European Sociological Review 12(1), 53-65.

Mechoulan, Stephane and Francois-Charles Wolff. 2015. "Intra-household allocation of family resources and birth order: evidence from France using sibling data." Journal of Population Economics 28(4), pp. 937-964.

Mendelsohn, M. B., Linden, J., Gruen, G., \& Curran, J. 1974. "Heterosexual pairing and sibling configuration." Journal of Individual Psychology, 30(2), pp. 202 - 210.

Mueller, C. W., \& Pope, H. 1977. "Marital instability: A test of its transmission between generations." Journal of Marriage and the Family, 39, pp. 83-9.

Paulhus, Delroy L., Paul D. Trapnell and David Chen. 1999. "Birth Order Effects on Personality and Achievement within Families" Psychological Science, 10(6), pp. 482-488.

Pilkington, Lloyd R., Joanna White, and Kenneth Matheny. 1997. "Perceived Coping Resources and Psychological Birth Order in School-Aged Children." Individual Psychology 53(1), pp. 42-58.

Polit, Denise and Toni Falbo. 1987 "Only children and personality development: A quantitative review" Journal of Marriage and the Family, 49(2), pp. 309-25.

Pollet, T. V., \& Nettle, D. 2007. "Birth order and face-to-face contact with a sibling: Firstborns have more contact than laterborns." Personality and Individual Differences, 43(1), pp. 796-1806.

Pollet, T.V., Dijkstra, P., Barelds, D.P.H., \& Buunk, A.P. 2010. "Birth order and the dominance aspect of extraversion: Are firstborns more extraverted, in the sense of being dominant, than laterborns?" Journal of Research in Personality, 44, pp. 742-745.

Record, Raymond, Thomas Mckeown, John Harvey Edwards. 1969. "The relation of measured intelligence to birth order and maternal age." Annals of Human Genetics 33, pp.61-69.

Richardson, Ronald W. and Lois A. Richardson. 1990. Birth Order and You. Bellingham: Self-Counsel Press.

Rohrer, Julia M., Boris Egloff and Stefan C. Schmukle, 2015. "Examining the effects of birth order on personality." Proceedings National Academy of Sciences 112, Pp. 14224-14229.

Salmon, C., Cuthbertson, A. M., Figueredo, A. J. 2016. "The relationship between birth order and prosociality: An evolutionary perspective." Personality and Individual Differences, 96, pp. 18-22.

Schooler, C. 1972. "Birth order effects: Not here, not now." Psychological Bulletin, 78(3), 161-175. 
Schuitemaker, Lisette and Wies Enthoven. 2016. The Eldest Daughter Effect. Forres: Findhorn Press.

Sills, Mary. 2010. "The implications of family size and birth order for test scores and behavioral development." Economics of Education Review 29, pp. 95-803.

Soons, J., Kalmijn, M., 2009. "Is marriage more than cohabitation? Well-being differences in 30 European countries." Journal of Marriage and Family 71, 1141- 1157.

Steelman, Lala C., Brian Powell, Regina Werum, and Scott Carter. 2002. "Reconsidering the effects of sibling onfiguration: Recent advances and challenges." Annual Review of Sociology, 28, pp. 243-69.

Sulloway, F. J. 1996. Born to rebel. New York: Pantheon Books.

Toman, W. 1971. "The duplication theorem of social relationships as tested in the general population." Psychological Review, 78(5), 380-390.

Toman, Walter. 1959. "Family Constellation as a Basic Personality Determinant." Journal of Individual Psychology, 15 pp. 199-211.

Toman, Walter. 1961; 1976. Family Constellation. New York: Springer.

Travis, Russell and Vandana Kohli. 1995. "The birth order factor: Ordinal position, socal strata, and educational achievement. Journal of Social Psychology, 135((4), pp. 499-507.

Webster, P. S., Orbuch, T. L., \& House, J. S. 1995. "Effects of childhood family background on adult marital quality and perceived stability." American Journal of Sociology, 101, pp. 404-43.

Weller, L., Natan, O., \& Hazi, O. 1974. "Birth Order and Marital Bliss in Israel. Journal of Marriage and the Family, 36, 794-797. 
Figure 1. Divorce Rate by Birth Order Position within Sibship Size

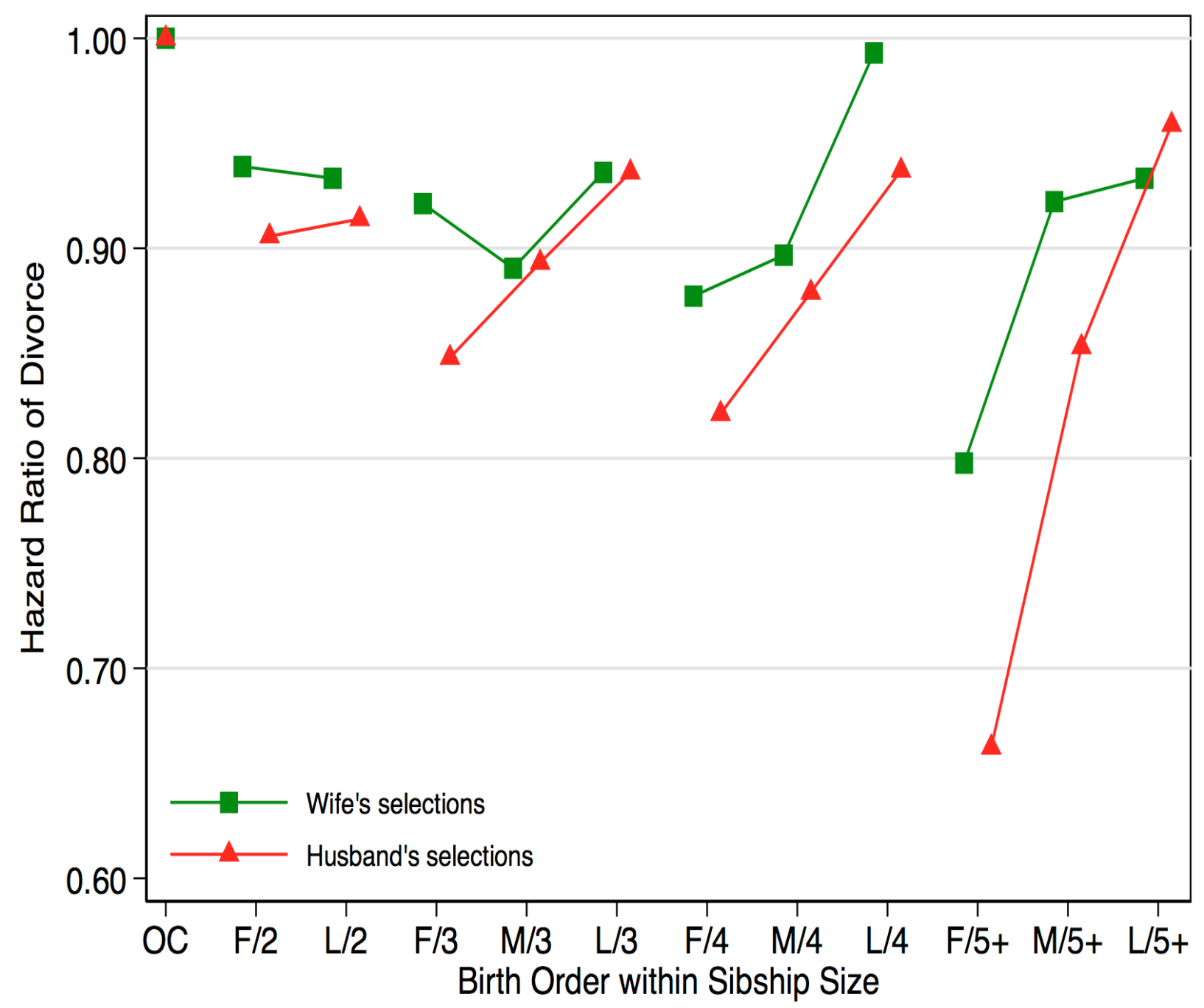

1. Effects are relative to only child. 
TABLE 1. CONTENTIONS OF LEEMAN AND BLAIR ${ }^{1}$

\begin{tabular}{cccccc} 
A. Contentions of Leeman $^{2}$ \\
\hline & & & & & \\
OC & F & M & L \\
OC & B & 0 & 0 & G \\
M & 0 & B & 0 & G \\
L & 0 & 0 & B & G \\
& & G & G & B \\
\hline
\end{tabular}

\begin{tabular}{cccccc} 
B. Contentions of & Blair & \\
\hline & & & & & \\
OC & F & M & L \\
\cline { 2 - 6 } & B & B & B & G & G \\
M & G & G & G & G \\
L & $\underline{G}$ & $\underline{G}$ & G & B \\
\hline
\end{tabular}

1. G = Hypothesized good marital pairing; $B=$ presumed bad pairing; $0=$ unremarked pairing. Bad pairings highlighted in bold.

2. Source: Leeman (2009)

3. Source: Blair (2011) 
TABLE 2. TESTS OF LEEMAN'S CONTENTIONS ${ }^{1}$

Panel A. No controls ${ }^{2}$

\begin{tabular}{|c|c|c|c|c|c|}
\hline & $\mathbf{r}$ & band in & first & positic & on \\
\hline & \multicolumn{4}{|c|}{ Wife } & \multirow[b]{2}{*}{$\mathbf{L}$} \\
\hline & & OC & $\mathbf{F}$ & $\mathbf{M}$ & \\
\hline $\mathrm{H}$ & OC & .033 & 0 & 0 & -.005 \\
\hline $\mathrm{u}$ & $\mathbf{F}$ & 0 & .000 & 0 & -.006 \\
\hline $\mathrm{s}$ & M & 0 & 0 & $-.067 *$ & -.046 \\
\hline $\mathrm{b}$ & L & $.093 *$ & .005 & .002 & 0 \\
\hline
\end{tabular}

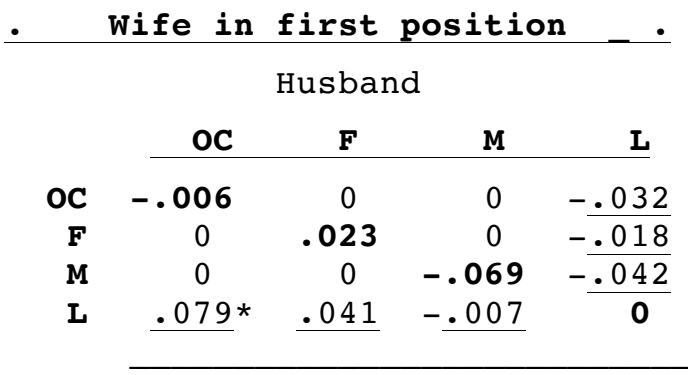

Summary test: Good $=-.027 ; \operatorname{Bad}=-.030 ;$ Other $(\operatorname{Ref})=0$.

Panel B. Controls present ${ }^{3}$

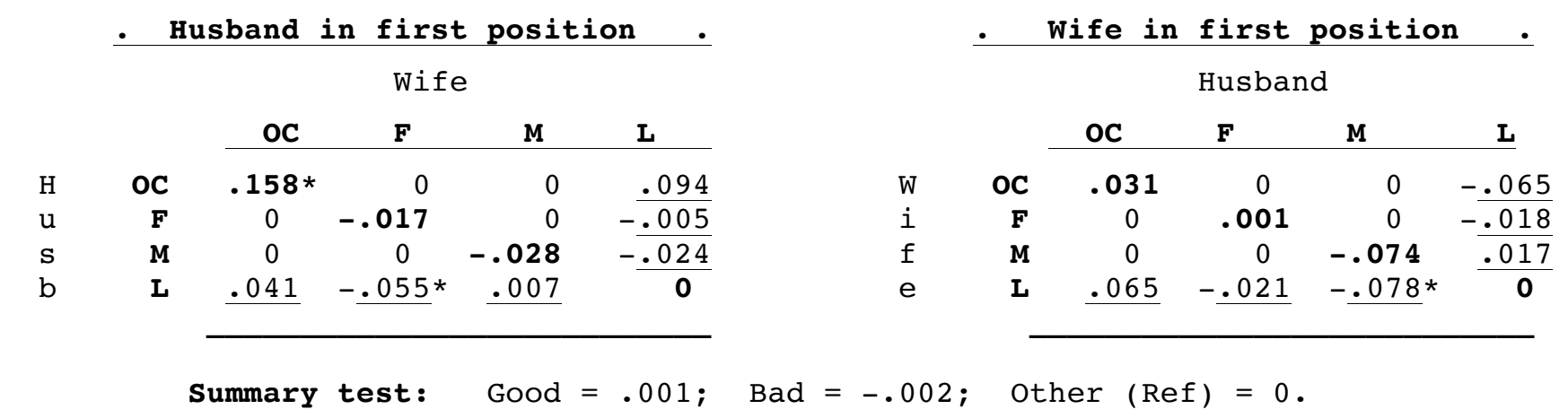

$* \mathrm{p}<.05 ; \quad * * \mathrm{p}<.01$

1. Entries are coefficients from a hazard model. Bad pairings appear in bold.

2. Year of birth terms included, but no substantive covariates.

3. Controls present for terms in Table A1 and year of marriage. 
TABLE 3. TESTS OF BLAIR'S CLAIMS ${ }^{1}$

Panel A. No controls ${ }^{2}$

- Husband in first position

Wife

\begin{tabular}{|c|c|c|c|c|c|}
\hline & & $\mathrm{OC}$ & $\mathrm{F}$ & $\mathrm{M}$ & $\mathrm{L}$ \\
\hline $\mathbf{H}$ & $\mathrm{OC}$ & 0 & -.065 & .038 & -.038 \\
\hline $\mathbf{u}$ & $\mathrm{F}$ & .052 & 0 & -.024 & -.006 \\
\hline $\mathbf{s}$ & M & $.206 * * *$ & .040 & 0 & .021 \\
\hline b & L & $.093 *$ & .005 & .002 & 0 \\
\hline
\end{tabular}

- Wife in first position _.

Husband

Summary test: $\operatorname{Good}=.001 ; \operatorname{Bad}(\operatorname{Ref})=0$

Panel B. Controls present ${ }^{3}$

- Husband in first position.

Wife

\begin{tabular}{|c|c|c|c|c|c|}
\hline & & OC & $\mathbf{F}$ & $\mathbf{M}$ & $\mathbf{L}$ \\
\hline H & OC & 0 & $-.183 *$ & -.004 & -.037 \\
\hline $\mathbf{u}$ & $\mathrm{F}$ & $.081 *$ & 0 & -.025 & .014 \\
\hline $\mathbf{s}$ & M & $.188 * *$ & .012 & 0 & .026 \\
\hline b & L & .041 & $-.055 *$ & .007 & 0 \\
\hline
\end{tabular}

Summary tests: $\operatorname{Good}=-.009 ; \operatorname{Bad}(\operatorname{Ref})=0$
- Wife in first position .

Husband

\begin{tabular}{|c|c|c|c|c|c|}
\hline & & OC & $\mathbf{F}$ & $\mathbf{M}$ & $\mathbf{L}$ \\
\hline W & OC & 0 & -.046 & .056 & -.079 \\
\hline $\mathbf{i}$ & $\mathrm{F}$ & .012 & 0 & -.009 & $-\overline{.019}$ \\
\hline f & M & $.230 * * *$ & +.057 & 0 & .112 * \\
\hline e & L & .065 & -.021 & $-.078 *$ & 0 \\
\hline
\end{tabular}

$* \mathrm{p}<\quad .05 ; \quad * * \mathrm{p}<.01$

1. Entries are coefficients from a hazard model. Bad pairings appear in bold.

2. Year of birth terms included, but no substantive covariates.

3. Controls present for terms in Table A1 and year of marriage. 
TABLE 4. THE CONTENTIONS OF WILLIAM CANE

A. Cane's Contentions ${ }^{1}$

Index ID

Best Pairing with Index ID

Worst Pairing

$\begin{array}{lllll}1 . & b(b \ldots b) & (b \ldots b) s & \text { or } & (s \ldots s) s \\ 2 . & (b \ldots b) b & s(b \ldots b) & \text { or } & s(s \ldots s) \\ 3 . & b(s \ldots s) & (b \ldots b) s & \text { or } & (s \ldots s) s \\ 4 . & (s \ldots s) b & s(b \ldots b) & \text { or } & s(s \ldots s) \\ 5 . & s(s \ldots s) & (s \ldots s) b & \text { or } & (b \ldots b) b \\ 6 . & (s \ldots s) s & b(s \ldots s) & \text { or } & b(b \ldots b) \\ 7 . & s(b \ldots b) & (b \ldots b) b & \text { or } & (s \ldots s) b \\ \text { 8. }(b \ldots b) s & b(s \ldots s) & \text { or } & b(b \ldots b) \\ 9 . & b=\text { oc } & s(b \ldots b) & \text { or } & s(s \ldots s) \\ 10 . & s=\text { oc } & b(s \ldots s) & \text { or } & b(b \ldots b)\end{array}$

$\mathbf{s}(\mathbf{b} \ldots \mathbf{b})$

(b..b)s or $(\mathrm{s} . \mathrm{s}) \mathrm{s}$

s(any siblings)

(s..s) $s$ or $s=O C$

b (b..b)

(b..b)b

b (b..b)

(b..b)b or $b=O C$

$\mathrm{s}=\mathrm{OC}$

$\mathbf{b}=\mathrm{OC}$

B. Assessment of Cane's Contentions ${ }^{2}$

\begin{tabular}{|c|c|c|c|c|}
\hline \multirow[b]{2}{*}{ Index ID } & \multicolumn{2}{|c|}{ No Control ${ }^{3}$} & \multicolumn{2}{|c|}{ Controls ${ }^{4}$} \\
\hline & Best & Worst & Best & Worst \\
\hline 1. $b(b \ldots b)$ & -.051 & .037 & -.022 & .055 \\
\hline 2. $(b \ldots b) b$ & .018 & -.022 & $-.090 *$ & -.058 \\
\hline 3. $b(s \ldots s)$ & -.006 & .033 & -.044 & -.021 \\
\hline 4. $(s \ldots s) b$ & .038 & $.094 *$ & .007 & .065 \\
\hline 5. $s(s \ldots s)$ & -.066 & -.048 & -.076 & $-.095 *$ \\
\hline 6. $(s \ldots s) s$ & -.013 & -.067 & -.007 & -.040 \\
\hline 7. $s(b \ldots b)$ & -.002 & .031 & .006 & .015 \\
\hline 8. (b..b)s & .041 & .036 & .011 & .039 \\
\hline 9. $b=O C$ & -.068 & .014 & $-.139 *$ & .040 \\
\hline 10. $s=O C$ & -.012 & .013 & .012 & .071 \\
\hline
\end{tabular}

${ }^{*} \mathbf{p}<.05 ; \quad * * \mathbf{p}<.01$

1. Source: Cane (2008).

2. Entries are coefficients from a hazard regression model.

3. Year of birth terms included, but no substantive covariates.

4. Controls present for terms in Table A1 and year of marriage. 
TABLE 5. THE CONTENTIONS OF WALTER TOMAN

A. Toman's Contentions ${ }^{1}$

Index ID

Best Pairing with index ID

Worst Pairing
1. $b(b . . b)$
(b..b)s
$\mathbf{s}(\mathbf{s} . \mathbf{s})$
2. (b..b)b
$s(b \ldots b)$
$(\mathrm{s} . \mathrm{s}) \mathrm{s}$
3. $b(s \ldots s)$
(b..b) $s$
$\mathbf{s}(\mathbf{s} . \mathbf{s})$
4. $(\mathrm{s} . \mathrm{s}) \mathrm{b}$
$s(b . . b)$
$(s \ldots s) s$
5. $s(s . . s)$
(s..s)b
b (b..b)
6. (s..s) $s$
$b(s . . s)$
(b..b) b
7. $s(b \ldots b)$
(s...s) b
b (b..b)
8. (b..b) $s$
b (s..s)
(b..b) b
9. $b=O C$
(b..b)s or $s(b \ldots b)$
$\mathbf{s}=\mathrm{OC}$
10. $s=O C$
(s..s)b or $b(s \ldots s)$
$\mathrm{b}=\mathrm{OC}$

B. Assessment of Toman's contentions ${ }^{2}$

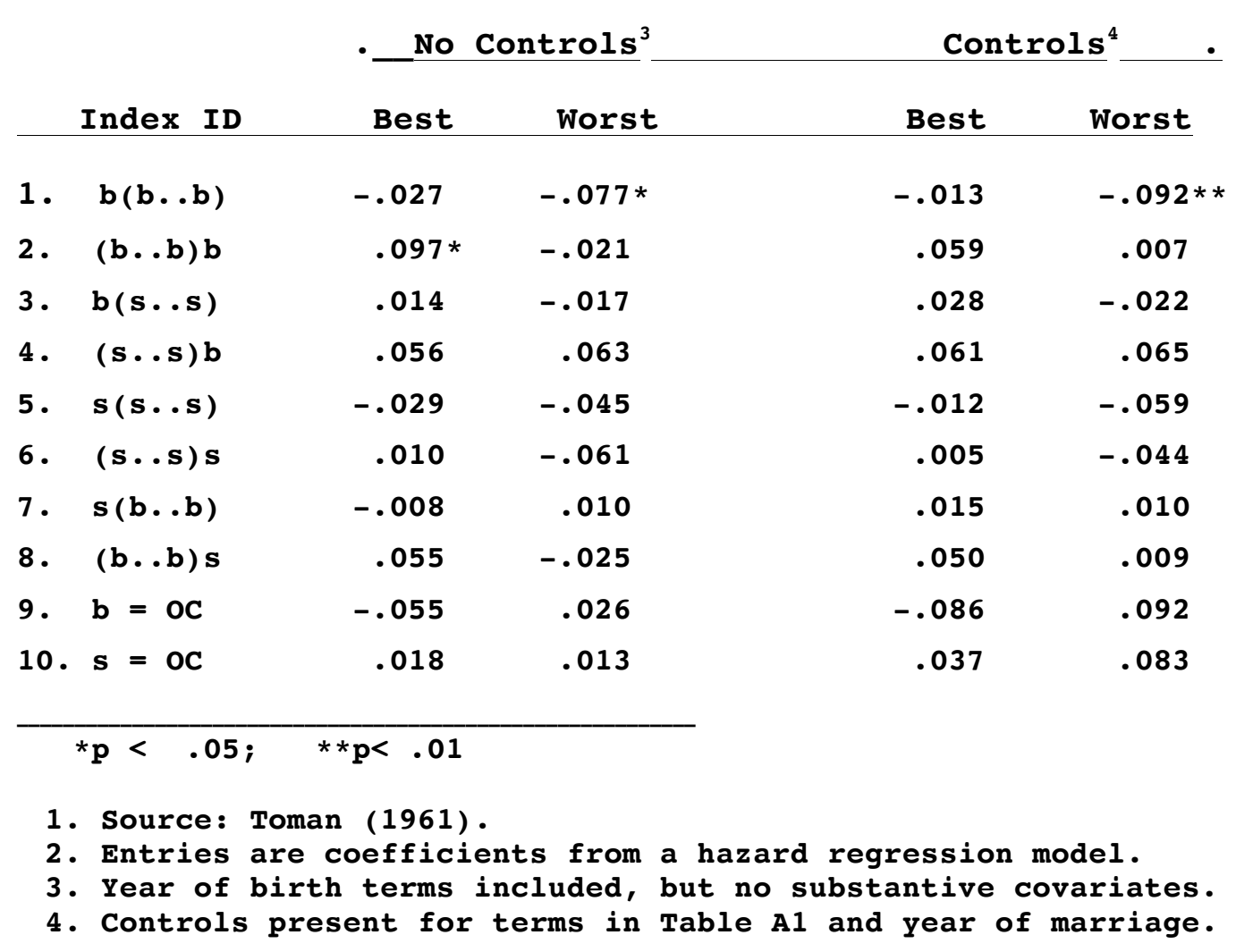


TABLE 6. EFFECTS OF BIRTH ORDER ON HAZARD OF DIVORCE ${ }^{1}$

A. Pairings by Husband's Birth Order

\begin{tabular}{lccccc} 
& \multicolumn{5}{c}{ Wife } \\
& & OC & F & M & L \\
& OC & 0.0 & $-.183 *$ & -.004 & -.037 \\
Husband & F & 0.0 & $-.081 *$ & $-.107 *$ & -.068 \\
& M & 0.0 & $-.176 *$ & $-.188 *$ & $-.162 * *$ \\
& L & 0.0 & $-.096 *$ & -.034 & -.041
\end{tabular}

B. Pairings by Wife's Birth Order

\begin{tabular}{rrrccc} 
& \multicolumn{5}{c}{ Husband } \\
& & OC & F & M & L \\
Wife & 0.0 & -.046 & .056 & -.079 \\
& F & 0.0 & -.013 & -.023 & -.033 \\
& M & 0.0 & $-.173 *$ & $-.231 * *$ & $-.119 *$ \\
& L & 0.0 & $-.086 *$ & $-.143 * *$ & -.064
\end{tabular}

$* p<.05 ; \quad * * p<.01$

1. Entries are coefficients from a hazard model. A separate regression was run for each row (index birth order), with oc serving as the reference term. Controls present for covariates in Table A1 and year of marriage. 
TABLE 7. Hazard of Divorce, by Birth Order Pairing within Sibship Size of Spouse ${ }^{1}$

\section{A. SPOUSAL SELECTIONS, BY HUSBAND'S BIRTH ORDER ${ }^{2}$}

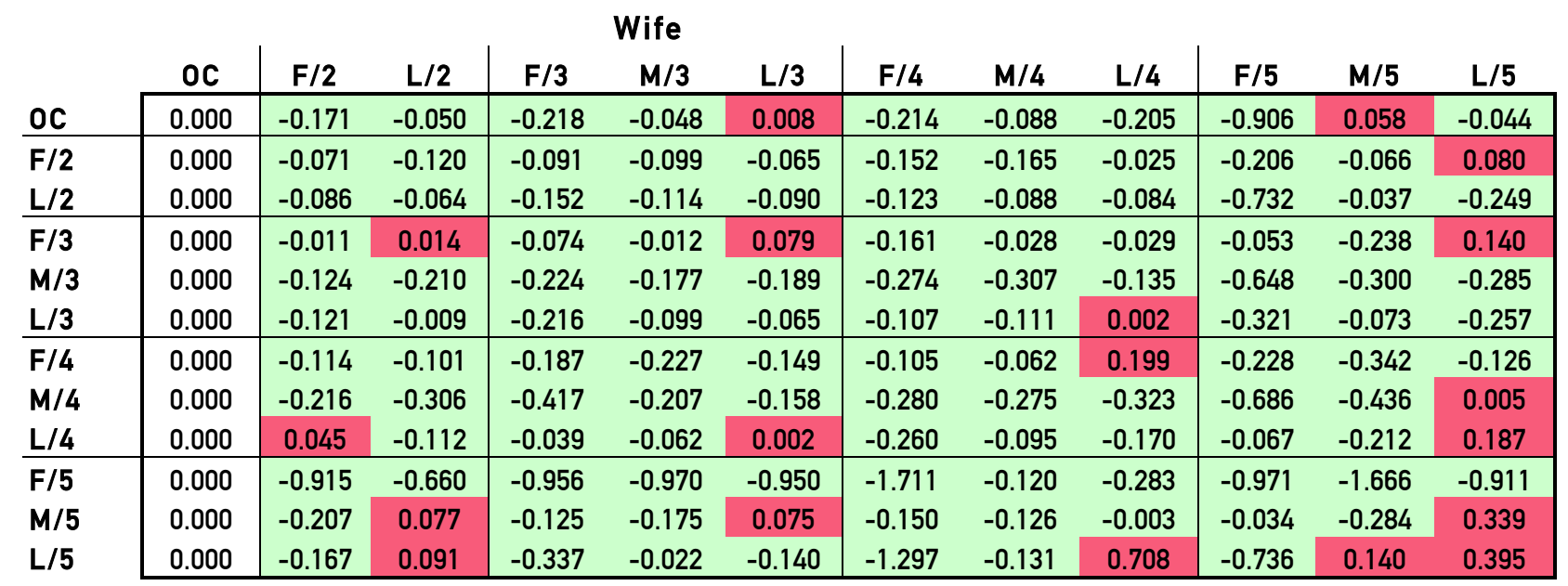

\section{B. SPOUSAL SELECTIONS, BY WIFE'S BIRTH ORDER ${ }^{2}$}

\begin{tabular}{|c|c|c|c|c|c|c|c|c|c|c|c|c|}
\hline \multicolumn{13}{|c|}{ Husband } \\
\hline & $\mathrm{OC}$ & $F / 2$ & $\mathrm{~L} / 2$ & F3 & $M / 3$ & $\mathrm{~L} / 3$ & $F / 4$ & $M / 4$ & $\mathrm{~L} / 4$ & $F / 5$ & $M / 5$ & $\mathrm{~L} / 5$ \\
\hline$O C$ & 0.000 & -0.042 & -0.082 & -0.144 & -0.015 & -0.144 & -0.100 & 0.066 & -0.125 & 0.245 & -0.049 & -0.133 \\
\hline$F / 2$ & 0.000 & -0.003 & -0.031 & -0.042 & -0.010 & -0.071 & -0.082 & -0.064 & 0.125 & -0.295 & -0.136 & -0.053 \\
\hline $\mathrm{L} / 2$ & 0.000 & -0.116 & -0.071 & -0.068 & -0.183 & -0.025 & -0.080 & -0.167 & -0.143 & -0.183 & 0.019 & -0.050 \\
\hline$F / 3$ & 0.000 & -0.020 & -0.094 & -0.105 & -0.116 & -0.149 & -0.168 & -0.302 & 0.084 & -0.386 & -0.100 & -0.173 \\
\hline$M / 3$ & 0.000 & -0.136 & -0.153 & -0.125 & -0.166 & -0.087 & -0.201 & -0.143 & -0.016 & -0.448 & -0.218 & -0.056 \\
\hline$L / 3$ & 0.000 & -0.104 & -0.093 & -0.059 & -0.190 & -0.075 & -0.236 & -0.012 & 0.001 & -0.372 & -0.025 & -0.196 \\
\hline $\mathrm{F} / 4$ & 0.000 & -0.093 & -0.007 & -0.235 & -0.119 & -0.038 & -0.239 & -0.166 & -0.156 & -1.755 & -0.130 & -1.391 \\
\hline$M / 4$ & 0.000 & -0.168 & -0.079 & -0.091 & -0.278 & -0.020 & -0.083 & -0.160 & 0.006 & 0.419 & -0.080 & -0.129 \\
\hline $\mathrm{L} / 4$ & 0.000 & 0.201 & 0.160 & 0.058 & 0.130 & 0.206 & 0.200 & 0.104 & -0.088 & 0.654 & 0.095 & 0.592 \\
\hline$L / 5$ & 0.000 & 0.224 & -0.347 & 0.553 & 0.043 & 0.168 & 0.236 & -0.361 & 0.046 & 0.159 & 0.604 & -0.277 \\
\hline$M / 5$ & 0.000 & -0.227 & -0.151 & -0.486 & -0.381 & -0.169 & -0.520 & -0.391 & -0.214 & -1.234 & -0.445 & 0.054 \\
\hline $\mathrm{L} / 5$ & 0.000 & 0.045 & -0.206 & 0.013 & -0.276 & -0.232 & -0.147 & 0.044 & 0.378 & -0.203 & 0.090 & 0.401 \\
\hline
\end{tabular}

1. Entries are coefficients from a hazard model. Separate regression estimated for each row, with marriage to an OC serving as the reference term.

2. Negative entry (green) indicates lower divorce rate than partnering with an oc; positive entry (red) indicates higher divorce rate.

3. Controls present for terms in Table A1. 
TABLE 8. Hazard of Divorce, by Birth Order Pairing within Sibship Size of Spouse 1

A. SPOUSAL SELECTIONS, BY HUSBAND'S BIRTH ORDER ${ }^{2}$

Wife

\begin{tabular}{|c|c|c|c|c|c|c|c|c|c|c|c|c|}
\hline & $O C$ & $F / 2$ & $\mathrm{~L} / 2$ & $F / 3$ & $\mathrm{M} / 3$ & $L / 3$ & $F / 4$ & $M / 4$ & $L / 4$ & $F / 5$ & $M / 5$ & $\mathrm{~L} / 5$ \\
\hline$O C$ & 0.000 & -0.171 & -0.050 & -0.218 & -0.048 & 0.008 & -0.214 & -0.088 & -0.205 & -0.906 & 0.058 & -0.044 \\
\hline$F / 2$ & 0.000 & -0.071 & -0.120 & -0.091 & -0.099 & -0.065 & -0.152 & -0.165 & -0.025 & -0.206 & -0.066 & 0.080 \\
\hline$\underline{L} / 2$ & 0.000 & -0.086 & -0.064 & -0.152 & -0.114 & -0.090 & -0.123 & -0.088 & -0.084 & -0.732 & -0.037 & -0.249 \\
\hline$F / 3$ & 0.000 & -0.011 & 0.014 & -0.074 & -0.012 & 0.079 & -0.161 & -0.028 & -0.029 & -0.053 & -0.238 & 0.140 \\
\hline$M / 3$ & 0.000 & -0.124 & -0.210 & -0.224 & -0.177 & -0.189 & -0.274 & -0.307 & -0.135 & -0.648 & -0.300 & -0.285 \\
\hline$\underline{L} / 3$ & 0.000 & -0.121 & -0.009 & -0.216 & -0.099 & -0.065 & -0.107 & -0.111 & 0.002 & -0.321 & -0.073 & -0.257 \\
\hline$F / 4$ & 0.000 & -0.114 & -0.101 & -0.187 & -0.227 & -0.149 & -0.105 & -0.062 & 0.199 & -0.228 & -0.342 & -0.126 \\
\hline$M / 4$ & 0.000 & -0.216 & -0.306 & -0.417 & -0.207 & -0.158 & -0.280 & -0.275 & -0.323 & -0.686 & -0.436 & 0.005 \\
\hline$\underline{L} / 4$ & 0.000 & 0.045 & -0.112 & -0.039 & -0.062 & 0.002 & -0.260 & -0.095 & -0.170 & -0.067 & -0.212 & 0.187 \\
\hline$F / 5$ & 0.000 & -0.915 & -0.660 & -0.956 & -0.970 & -0.950 & -1.711 & -0.120 & -0.283 & -0.971 & -1.666 & -0.911 \\
\hline$M / 5$ & 0.000 & -0.207 & 0.077 & -0.125 & -0.175 & 0.075 & -0.150 & -0.126 & -0.003 & -0.034 & -0.284 & 0.339 \\
\hline$L / 5$ & 0.000 & -0.167 & 0.091 & -0.337 & -0.022 & -0.140 & -1.297 & -0.131 & 0.708 & -0.736 & 0.140 & 0.395 \\
\hline
\end{tabular}

B. SPOUSAL SELECTIONS, BY WIFE'S BIRTH ORDER ${ }^{2}$

Husband

\begin{tabular}{|c|c|c|c|c|c|c|c|c|c|c|c|c|}
\hline & $O C$ & $\mathrm{~F} / 2$ & $\mathrm{~L} / 2$ & $F / 3$ & $\mathrm{M} / 3$ & $\mathrm{~L} / 3$ & $F / 4$ & $M / 4$ & $\mathrm{~L} / 4$ & $F / 5$ & $M / 5$ & $\mathrm{~L} / 5$ \\
\hline$O C$ & 0.000 & -0.042 & -0.082 & -0.144 & -0.015 & -0.144 & -0.100 & 0.066 & -0.125 & 0.245 & -0.049 & -0.133 \\
\hline \multirow{2}{*}{$\begin{array}{l}F / 2 \\
L / 2\end{array}$} & 0.000 & -0.003 & -0.031 & -0.042 & -0.010 & -0.071 & -0.082 & -0.064 & 0.125 & -0.295 & -0.136 & -0.053 \\
\hline & 0.000 & -0.116 & -0.071 & -0.068 & -0.183 & -0.025 & -0.080 & -0.167 & -0.143 & -0.183 & 0.019 & -0.050 \\
\hline$F / 3$ & 0.000 & -0.020 & -0.094 & -0.105 & -0.116 & -0.149 & -0.168 & -0.302 & 0.084 & -0.386 & -0.100 & -0.173 \\
\hline$/ 3$ & 0.000 & -0.136 & -0.153 & -0.125 & -0.166 & -0.087 & -0.201 & -0.143 & -0.016 & -0.448 & -0.218 & -0.056 \\
\hline$L / 3$ & 0.000 & -0.104 & -0.093 & -0.059 & -0.190 & -0.075 & -0.236 & -0.012 & 0.001 & -0.372 & -0.025 & -0.196 \\
\hline$F / 4$ & 0.000 & -0.093 & -0.007 & -0.235 & -0.119 & -0.038 & -0.239 & -0.166 & -0.156 & -1.755 & -0.130 & -1.391 \\
\hline$M / 4$ & 0.000 & -0.168 & -0.079 & -0.091 & -0.278 & -0.020 & -0.083 & -0.160 & 0.006 & 0.419 & -0.080 & -0.129 \\
\hline$L / 4$ & 0.000 & 0.201 & 0.160 & 0.058 & 0.130 & 0.206 & 0.200 & 0.104 & -0.088 & 0.654 & 0.095 & 0.592 \\
\hline$F / 5$ & 0.000 & 0.224 & -0.347 & 0.553 & 0.043 & 0.168 & 0.236 & -0.361 & 0.046 & 0.159 & 0.604 & -0.277 \\
\hline$M / 5$ & 0.000 & -0.227 & -0.151 & -0.486 & -0.381 & -0.169 & -0.520 & -0.391 & -0.214 & -1.234 & -0.445 & 0.054 \\
\hline L/5 & 0.000 & 0.045 & -0.206 & 0.013 & -0.276 & -0.232 & -0.147 & 0.044 & 0.378 & -0.203 & 0.090 & 0.401 \\
\hline
\end{tabular}

1. Entries are coefficients from a hazard model. Separate regression estimated for each row, with marriage to an OC serving as the reference term.

2. Negative entry (green) indicates lower divorce rate than partnering with an oc; positive entry (red) indicates higher divorce rate.

3. Controls present for terms in Table A1. 
TABLE A1. CONTROL VARIABLES IN THE ANALYSIS

\begin{tabular}{|c|c|c|c|c|c|}
\hline Variable & Category & Frequency (\%) & $\begin{array}{r}\text { Person- } \\
\text { months \% }\end{array}$ & Divorces (\%) & $\begin{array}{r}\text { Divorce } \\
\text { Rate } \\
10-4\end{array}$ \\
\hline Husband's & $15-19$ & 9,247 (3.9) & 4.3 & $1,887(6.0)$ & 15.3 \\
\hline \multirow[t]{4}{*}{ mother's age at birth } & $20-24$ & $64,444(27.4)$ & 27.7 & 9,830 (31.4) & 12.3 \\
\hline & $25-29$ & $90,689(38.6)$ & 37.4 & $11,043(35.3)$ & 10.2 \\
\hline & $30-34$ & $48,406(20.6)$ & 20.1 & 5,524 (17.7) & 9.5 \\
\hline & $35+$ & $22,422(9.5)$ & 10.6 & $2,988(9.6)$ & 9.8 \\
\hline Wife's & $15-19$ & 8,775 (3.7) & 4.2 & $1,826(5.8)$ & 15.2 \\
\hline \multirow[t]{4}{*}{ mother's age at birth } & $20-24$ & $64,400(27.4)$ & 28.1 & 10,139 (32.4) & 12.5 \\
\hline & $25-29$ & $91,974(39.1)$ & 37.9 & $11,289(36.1)$ & 10.3 \\
\hline & $30-34$ & $48,808(20.8)$ & 20.0 & $5,437(17.4)$ & 9.4 \\
\hline & $35+$ & $21,251(9.0)$ & 9.8 & $2,581(8.3)$ & 9.1 \\
\hline Husband's & Pre-Gymnasium & $82,925(35.3)$ & 38.4 & $12,704(40.6)$ & 11.5 \\
\hline \multirow[t]{4}{*}{ father's education } & Gymnasium & $51,917(22.1)$ & 20.8 & $6,907(22.1)$ & 11.5 \\
\hline & $<3$ Years Tertiary & $39,271(16.7)$ & 16.4 & $5,067(16.2)$ & 10.7 \\
\hline & $3+$ Years Tertiary & $58,514(24.9)$ & 23.0 & 6,125 (19.6) & 9.2 \\
\hline & Missing & $2,581(1.1)$ & 1.4 & 469 (1.5) & 11.2 \\
\hline Husband's & Pre-Gymnasium & $72,521(30.8)$ & 35.7 & $11,872(38.0)$ & 11.5 \\
\hline \multirow[t]{4}{*}{ mother's education } & Gymnasium & $81,753(34.8)$ & 33.8 & $11,032(35.3)$ & 11.3 \\
\hline & $<3$ Years Tertiary & $16,567(7.0)$ & 6.0 & $1,833(5.9)$ & 10.6 \\
\hline & $3+$ Years Tertiary & $63,566(27.0)$ & 24.0 & $6,381(20.4)$ & 9.2 \\
\hline & Missing & $801(0.3)$ & 0.4 & $154(0.5)$ & 12.1 \\
\hline Wife's & Pre-Gymnasium & $80,017(34.0)$ & 37.1 & $11,946(38.2)$ & 11.1 \\
\hline \multirow[t]{4}{*}{ father's education } & Gymnasium & $55,159(23.5)$ & 22.1 & $7,352(23.5)$ & 11.5 \\
\hline & $<3$ Years Tertiary & $39,237(16.7)$ & 16.6 & $5,296(16.9)$ & 11.0 \\
\hline & $3+$ Years Tertiary & $59,038(25.1)$ & 23.3 & 6,342 (20.3) & 9.4 \\
\hline & Missing & $1,757(0.8)$ & 0.9 & $336(1.1)$ & 12.4 \\
\hline
\end{tabular}




\begin{tabular}{|c|c|c|c|c|c|}
\hline Wife's & Pre-Gymnasium & $65,953(28.0)$ & 32.7 & $10,462(33.5)$ & 11.1 \\
\hline \multirow[t]{4}{*}{ mother's education } & Gymnasium & $84,721(36.0)$ & 35.4 & $11,840(37.9)$ & 11.6 \\
\hline & $<3$ Years Tertiary & $18,172(7.7)$ & 6.6 & $2,121(6.8)$ & 11.1 \\
\hline & $3+$ Years Tertiary & $65,806(28.0)$ & 25.0 & $6,767(21.6)$ & 9.3 \\
\hline & Missing & $556(0.2)$ & 0.3 & $82(0.3)$ & 9.6 \\
\hline Husband's father's & I & $4,147(1.8)$ & 1.6 & $447(1.4)$ & 9.7 \\
\hline \multirow[t]{5}{*}{ social class (EGP) } & ॥ & 69,061 (29.4 & 31.2 & $9,060(29.0)$ & 10.0 \\
\hline & III & $3,434(1.5)$ & 0.9 & $327(1.0)$ & 12.1 \\
\hline & IV & $21,217(9.0)$ & 10.5 & 2,782 (8.9) & 9.2 \\
\hline & VI-VII & $98,891(42.0)$ & 41.7 & $14,515(46.4)$ & 12.0 \\
\hline & Unknown & $38,458(16.4)$ & 14.1 & 4,141 (13.2) & 10.2 \\
\hline Wife's father's & 1 & $4,312(1.8)$ & 1.5 & $405(1.3)$ & 9.4 \\
\hline \multirow[t]{5}{*}{ social class (EGP) } & II & $64,397(27.4)$ & 29.3 & $8,627(27.6)$ & 10.2 \\
\hline & III & $4,146(1.8)$ & 1.1 & $394(1.3)$ & 12.8 \\
\hline & IV & $19,413(8.3)$ & 9.6 & 2,466 (7.9) & 8.9 \\
\hline & VI-VII & $102,057(43.4)$ & 43.1 & $14,800(47.3)$ & 11.9 \\
\hline & Unknown & $40,883(17.4)$ & 15.4 & $4,580(14.6)$ & 10.3 \\
\hline Husband's parents & No & $223,944(95.2)$ & 96.0 & 29,417 (94.1) & 10.6 \\
\hline divorced before age 14 & Yes & $11,264(4.8)$ & 4.0 & $1,855(5.9)$ & 16.0 \\
\hline Wife's parents & No & $222,818(94.7)$ & 95.5 & $28,889(92.4)$ & 10.5 \\
\hline divorced before age 14 & Yes & $12,390(5.3)$ & 4.5 & $2,383(7.6)$ & 18.4 \\
\hline Husband's parent & No & $230,834(98.1)$ & 98.0 & $30,590(97.8)$ & 10.8 \\
\hline died before age 14 & Yes & $4,374(1.9)$ & 2.0 & $682(2.2)$ & 12.1 \\
\hline Wife's parent & No & $230,822(98.1)$ & 98.0 & $30,543(97.7)$ & 10.8 \\
\hline died before age 14 & Yes & 4,386 (1.9) & 2.0 & $729(2.3)$ & 12.9 \\
\hline Husband's age & $16-20$ & $576(0.2)$ & 0.3 & $164(0.5)$ & 19.7 \\
\hline \multirow[t]{2}{*}{ at marriage } & $21-25$ & $20,089(8.5)$ & 10.8 & $4,384(14.0)$ & 14.1 \\
\hline & $26-30$ & $81,984(34.9)$ & 39.8 & $12,831(41.0)$ & 11.2 \\
\hline
\end{tabular}




\begin{tabular}{|c|c|c|c|c|c|}
\hline & $31-45$ & $75,865(32.3)$ & 31.1 & $9,136(29.2)$ & 10.2 \\
\hline & $36-40$ & $36,831(15.7)$ & 12.9 & $3,605(11.5)$ & 9.6 \\
\hline & $41-45$ & $12,873(5.5)$ & 3.8 & $927(3.0)$ & 8.5 \\
\hline & $46-50$ & $4,688(2.0)$ & 1.1 & $203(0.6)$ & 6.6 \\
\hline & $51-62$ & $2,302(1.0)$ & 0.3 & $22(0.1)$ & 2.3 \\
\hline Husband-Wife & Wife older, $>4$ years & $7,445(3.2)$ & 3.0 & $1,127(3.6)$ & 13.2 \\
\hline \multirow[t]{5}{*}{ age difference } & $\begin{array}{l}\text { Wife older, } 1-4 \text { years } \\
\text { Age difference up to } 12\end{array}$ & $25,294(10.8)$ & 10.5 & $3,227(10.3)$ & 10.6 \\
\hline & months & $63,129(26.8)$ & 26.7 & 7,459 (23.9) & 9.7 \\
\hline & Husband older, 1-4 years & $86,735(36.9)$ & 37.8 & $11,234(35.9)$ & 10.3 \\
\hline & Husband older, 5-6 years & 28,075 (11.9) & 12.0 & $4,083(13.1)$ & 11.8 \\
\hline & Husband older, $>6$ years & $24,530(10.4)$ & 10.1 & $4,142(13.2)$ & 14.2 \\
\hline Husband educational & Pre-Gymnasium & $16,240(6.9)$ & 7.8 & $3,566(11.4)$ & 15.9 \\
\hline \multirow[t]{4}{*}{ level } & Gymnasium & $64,043(27.2)$ & 31.7 & $12,143(38.8)$ & 13.3 \\
\hline & $<3$ Years Tertiary & $47,757(20.3)$ & 16.8 & $5,613(17.9)$ & 11.6 \\
\hline & $3+$ Years Tertiary & $106,215(45.2)$ & 43.3 & $9,832(31.4)$ & 7.9 \\
\hline & Missing & $953(0.4)$ & 0.4 & $118(0.4)$ & 9.4 \\
\hline Husband-Wife & Husband $=$ Wife & $125,156(53.2)$ & 51.2 & $14,409(46.1)$ & 9.7 \\
\hline \multirow[t]{3}{*}{ educational difference } & Husband $>$ Wife & $38,663(16.4)$ & 18.5 & $7,040(22.5)$ & 13.2 \\
\hline & $\begin{array}{l}\text { Husband }<\text { Wife } \\
\text { Husband | Wife data }\end{array}$ & $70,254(29.9)$ & 29.8 & $9,675(30.9)$ & 11.2 \\
\hline & missing & $1,135(0.5)$ & 0.5 & $148(0.5)$ & 10.5 \\
\hline Husband/Wife had a child with & No & $226,485(96.3)$ & 96.4 & 29,291 (93.7) & 10.5 \\
\hline third partner before marriage & Yes & $8,723(3.7)$ & 3.6 & $1,981(6.3)$ & 18.9 \\
\hline $\begin{array}{l}\text { Husband-Wife childbearing } \\
\text { before marriage }\end{array}$ & No & $167,307(71.1)$ & 72.3 & $20,893(66.8)$ & 10.0 \\
\hline within partnership & Yes & $67,901(28.9)$ & 27.7 & $10,379(33.2)$ & 13.0 \\
\hline Total & & $235,208(100.0)$ & 100.0 & $31,272(100.0)$ & 10.8 \\
\hline
\end{tabular}

